\title{
Amplification generates modular diversity at an avirulence locus in the pathogen Phytophthora
}

\author{
Rays H.Y. Jiang, ${ }^{1}$ Rob Weide, ${ }^{1}$ Peter J.I. van de Vondervoort, and Francine Govers ${ }^{2}$ \\ Laboratory of Phytopathology, Plant Sciences Group, Wageningen University, NL-5-6709 PD Wageningen \\ and Graduate School Experimental Plant Sciences, The Netherlands
}

\begin{abstract}
The destructive late blight pathogen Phytophthora infestans is notorious for its rapid adaptation to circumvent detection mediated by plant resistance $(R)$ genes. We performed comparative genomic hybridization on microarrays (array-CGH) in a near genome-wide survey to identify genome rearrangements related to changes in virulence. Six loci with copy number variation were found, one of which involves an amplification colocalizing with a previously identified locus that confers avirulence in combination with either $R$ gene $R 3 b$, R1O, or R11. Besides array-CGH, we used three independent approaches to find candidate genes at the Avr3b-Avr10-Avr11 locus: positional cloning, cDNA-AFLP analysis, and Affymetrix array expression profiling. This resulted in one candidate, pi3.4, that encodes a protein of 1956 amino acids with regulatory domains characteristic for transcription factors. Amplification is restricted to the $3^{\prime}$ end of the full-length gene but the amplified copies still contain the hallmarks of a regulatory protein. Sequence comparison showed that the amplification may generate modular diversity and assist in the assembly of novel full-length genes via unequal crossing-over. Analyses of $P$. infestans field isolates revealed that the pi3.4 amplification correlates with avirulence; isolates virulent on R3b, R10, and R11 plants lack the amplified gene cluster. The ancestral state of 3.4 in the Phytophthora lineage is a full-length, single-copy gene. In P. infestans, however, pi3.4 is a dynamic gene that is amplified and has moved to other locations. Modular diversity could be a novel mechanism for pathogens to quickly adapt to changes in the environment.
\end{abstract}

[Supplemental material is available online at www.genome.org. The sequence data from this study have been submitted to GenBank under accession nos. DQ390339, DQ390340, and DQ390341.]

Micro organisms that are successful as pathogens often have flexible genomes. In bacterial pathogens gene flow caused by horizontal gene transfer is a key event to gain pathogenicity (Schmidt and Hensel 2004) and gene amplifications can lead to increased virulence (Romero and Palacios 1997). In eukaryotic pathogens genomic rearrangements can play a critical role in creating antigenic variation to evade host defense responses (Vanhamme and Pays 1995). Genome plasticity also contributes to the success of many different classes of plant pathogens. For example, loss of elicitor genes to evade host detection has been described in several plant pathogenic fungi (van Kan et al. 1991; Rohe et al. 1995; Westerink et al. 2004), and also genomic rearrangements in unstable repeat-rich, subtelomeric regions and transposon insertions generating new virulent alleles have been reported (Orbach et al. 2000). Rearrangements within coding regions can also result in changes in virulence. Due to the variation in the number of repeats in the AvrBs3 elicitor family of plant pathogenic Xanthomonas spp. host specificity of these bacteria can change rapidly (Leach and White 1996). Many plant pathogenic bacteria utilize a type III secretion system (TTSS) to inject effectors into plant cells (Alfano and Collmer 2004). TTSS effector genes often reside on hyper-variable regions with frequent rearrangements that can lead to changes in virulence (Alfano et al. 2000).

Plant pathogens with a high evolutionary potential are more likely to overcome genetic resistance in the host plant than those with a low evolutionary potential. Factors determining evolutionary potential include gene flow, population size, muta-

\footnotetext{
1These authors contributed equally to this work.

${ }^{2}$ Corresponding author.

E-mail Francine.Govers@wur.nl; fax +31-317-483412.

Article is online at http://www.genome.org/cgi/doi/10.1101/gr.5193806.
}

tion rate, and reproduction system (sexual or asexual). Phytophthora infestans, the potato late blight pathogen, has a high evolutionary potential (McDonald and Linde 2002). Late blight led to the Irish potato famine in the mid 1840s and resulted in the death or displacement of millions of people (Bourke 1993). Until today this disease continues to cause huge losses worldwide. The genus Phytophthora comprises over 65 notorious plant pathogens that not only cause considerable damage to many commercially grown crops but also to natural vegetations (Nicholls 2004). Phytophthora is a fungus-like organism but unrelated to fungi. It is classified as a Stramenopile together with diatoms and brown algae.

A classical strategy to fight pathogens in agricultural settings is to breed for resistance. Natural resistance found in wild relatives is introgressed in crop plants and often provides specific resistance to particular races or pathotypes of a pathogen. This high specificity between a particular host (cultivar) and pathogen (race) genotype is the basis of the gene-for-gene hypothesis launched by Flor and Oort in the 1940s (Flor 1942) and confirmed by the molecular and functional identification of plant resistance genes ( $R$ genes) and matching avirulence ( $A v r)$ genes in the pathogen (van't Slot and Knogge 2002). Breeding in potato (Solanum tuberosum) using the Mexican species Solanum demissum resulted in 11 independent potato lines showing race-specific late blight resistance (Wastie 1991). According to the gene-forgene hypothesis, 11 corresponding Avr genes are anticipated, and genetic analyses on $P$. infestans could indeed confirm this (Spielman et al. 1989; Al-Kherb et al. 1995; van der Lee et al. 2001a). Unfortunately, soon after the resistant potato lines were exposed to natural $P$. infestans populations new races appeared that could overcome the resistance (Wastie 1991). Presumably, the Avr 
genes undergo rapid changes so that the pathogen evades detection by the introgressed $R$ genes.

$P$. infestans is absolutely notorious for its ability to change in response to $R$ genes, and such adaptive changes may be accelerated by the genome plasticity of $P$. infestans. Field isolates are genetically highly variable, not only in Central America, the center of origin of $P$. infestans, but also in North America and Western Europe (Goodwin et al. 1992, 1998; Zwankhuizen et al. 1998). Polyploidy, aneuploidy, and trisomy are found in field isolates (Tooley and Therrien 1987; Gu et al. 1993; Carter et al. 1999; van der Lee et al. 2004), and chromosomal deletions and translocations related to virulence and mating behavior have been described (Judelson 1996; van der Lee et al. 2001b). P. infestans has many transposon(-like) elements that are known to contribute to genome plasticity. In syntenic regions $P$. infestans (with a genome size of $240 \mathrm{Mb}$ ) possesses larger intergenic regions as compared with other species and this is mainly due to the abundance of heterogeneous transposons interspersed between genes (Jiang et al. 2006).

Previously we identified a locus in $P$. infestans that carries three closely linked dominant Avr genes, Avr3, Avr10, and Avr11 (van der Lee et al. 2001a, 2004). We have strong indications that a change in phenotype on $R 3 b, R 10$, and $R 11$ potato lines is associated with a genome rearrangement or chromosomal deletion at that locus (van der Lee et al. 2001b). Avr3 has recently been renamed to $A v r 3 b$ to indicate that this $A v r$ gene elicits resistance on plants carrying $R 3 b$ but not $R 3 a$ (Huang et al. 2004). The Avr $3 b-A v r 10-A v r 11$ locus resides in a subtelomeric region. In the avirulent parent and progeny of a mapping population (cross 71 , see Methods) this locus is hemizygous and contains a number of high copy repeat sequences (van der Lee et al. 2001b). In contrast, the virulent parent and progeny lack these repeats and have a chromosomal deletion in the vicinity of the $A v r$ locus that could span the Avr genes. Also in a diverse set of field isolates that are virulent on $R 3 b, R 10$, and $R 11$ potato lines $A v r 3 b-A v r 10$ Avr11-linked markers are absent, suggesting a similar chromosomal deletion (van der Lee et al. 2001b). To further investigate the correlation between genome rearrangements and the avirulence phenotype, we need a more in depth analysis of the structural organization of the genes residing at this locus.

To clone the Avr locus we initially adopted a positional cloning approach. AFLP markers tightly linked to Avr $3 b, A v r 10$, and Avr11 were used to screen a BAC library. The resulting BAC contig partially spanned the locus (Whisson et al. 2001), but repeat sequences at the BAC ends and the lack of recombinants hampered extending the BAC contig by chromosome walking. In parallel we performed cDNA-AFLP expression profiling with the aim to identify $A v r$-associated transcripts. The cDNA-AFLP template was RNA isolated from germinating cysts where Avr genes are expected to be expressed. Genome-wide screening using bulked segregant analysis (BSA) was performed on pools of F1 progeny that differed in their virulence phenotypes and resulted in a number of transcript-derived fragments (TDFs) unique for avirulent strains (Guo et al. 2006).

For the present study we used the Avr $3 b-A v r 10-A v r 11$-linked AFLP markers (van der Lee et al. 2001a), the initial BAC contig (Whisson et al. 2001), and the Avr3b-Avr10-Avr11-associated TDFs (Guo et al. 2006) as a starting point for cloning the locus. We extended the BAC contig using $A v r$-associated TDFs and selected additional transcriptome markers by screening a custommade Phytophthora GeneChip composed of 18,256 unigenes. Six markers obtained via three different approaches all landed within a 10-kb region comprising an open reading frame (ORF). Comparison of the avirulent and virulent haplotype revealed a remarkable amplification of truncated copies of the ORF in the avirulent haplotype that could function as a source of modules for generating novel genes. Assembly of existing gene modules is a significant mechanism for evolution of novel biological functions (Patthy 2003; Tordai et al. 2005). To determine whether copy number variation (CNV) is related to virulence, we performed array-based comparative genomic hybridization (arrayCGH), a method that can detect amplifications and deletions at a genome-wide scale (Lucito et al. 2003; Vissers et al. 2005). Array-CGH revealed CNV at six loci, one of which is the Avr $3 b-A v r 10$ Avr11 locus. Comparison with $P$. sojae and P. ramorum showed that the Avr3b-Avr10-Avr11 locus in P. infestans is highly rearranged. The biological relevance of the rearrangement and the modular diversity at the Avr $3 b-A v r 10-A v r 11$ locus are discussed.

\section{Results}

Isolation of two cDNA-AFLP fragments cosegregating with the Avr3b-Avr10-Avr11 locus

Previously, we used a cDNA-AFLP-based strategy to identify transcripts associated with avirulence and this resulted in two TDFs showing $100 \%$ association with the AVR3b-AVR10-AVR11 phenotype (Guo et al. 2006). Based on the sequence of TDF3.1 and TDF3.4 primers were designed to confirm the transcript polymorphism by RT-PCR. RNA isolated from germinating cysts from the two parental strains and nine F1 progenies was analyzed and, indeed, TDF3.1 and TDF3.4 showed a polymorphism that correlates with the AVR3b-AVR10-AVR11 phenotype (Fig. 1). RT-PCR with TDF3.4 primers resulted in a 115-bp RT-PCR product in avirulent strains whereas the product was absent in virulent strains. RT-PCR with TDF3.1 primers resulted in a clear amplification product of $54 \mathrm{bp}$ in avirulent strains. In contrast, virulent strains had a less intense band that was a few bp larger in size. These results show that in the mapping population TDF3.1 and TDF3.4 cosegregate with the Avr3b-Avr10-Avr11 locus.

\section{TDF3.4 and TDF3.1 are located on a linkage group VIII BAC contig that comprises the Avr3b-Avr10-Avr11 locus}

Genomic Southern blot analysis was performed with DNA isolated from the two parental strains 80029 and 88133 and digested with PstI and EcoRI. TDF3.1 hybridized to two fragments and showed a clear polymorphism: The fragments are only pres-

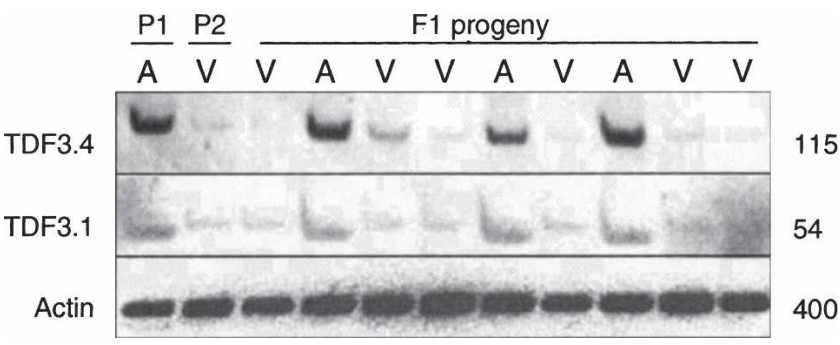

Figure 1. Expression of two candidate TDFs in germinating cysts of different $P$. infestans strains. RT-PCR of TDF3.4 and TDF3.1 on the two parental strains of the mapping population, 80029 (P1) and 88133 (P2), and nine F1 progenies. The sizes of the amplification products (bp) are on the right. A stands for avirulent and refers to strains with AVR3b-AVR10 AVR11 phenotype, whereas $V$ stands for virulence for strains with the avr3b-avr10-avr11 phenotype. 
ent in the avirulent parent 80029 (Fig. 2A), indicating that the virulent parent lacks a TDF3.1 homolog. In contrast, TDF3.4 hybridized to several restriction fragments with different intensities and with polymorphism between the parents (Fig. 2B), suggesting that TDF3.4 represents a gene family.

Screening of a $10 \times$ coverage BAC library of strain T30-4 with TDF3.4 resulted in over 50 hybridizing BACs. This large number is consistent with the presence of multiple loci in the genome. T30-4 is an F1 progeny of strains 80029 and 88133 and heterozygous at the Avr $3 b-A v r 10-A v r 11$ locus. The dominant allele is inherited from 80029. Forty positive BACs including two that hybridized much stronger than the others (34G01 and 40D03) were fingerprinted by restriction analyses, and Southern blots containing BglII-digested BAC DNA were hybridized. Based on fingerprinting and TDF3.4 hybridization, six BAC contigs could be distinguished (Supplemental Table S1). With TDF3.1 as probe three BACs, including 34G01 and 40D03, gave a clear signal. These three belong to contig-I, demonstrating that this contig is shared by both TDF3.4 and TDF3.1.

Previously we identified a minimum tiling path of four BACs partially spanning the $A v r 3 b-A v r 10-A v r 11$ locus (Whisson et al. 2001). Those BACs were selected by screening threedimensional pools of the BAC library with AFLP markers located on Linkage Group VIII and linked to Avr $3 b-A v r 10-A v r 11$. In that screening we identified two additional BACs having the $A v r 3 b$ Avr10-Avr11 cosegregating AFLP marker E+AA/M+CTs239 but they could not be integrated in the minimal tiling path contig. These were identified as 34G01 and 40D03, the BACs that hybridized strongly with TDF3.4. Four BACs assigned to contig-I can now be bridged with the minimum tiling path (defined as contig-0) via BAC22O12 (Fig. 3A). The other contig-I BACs did not show up as positives when screening the library with Avrlinked AFLP markers nor did they hybridize to TDF3.1. We therefore assume that they represent the virulent haplotype.

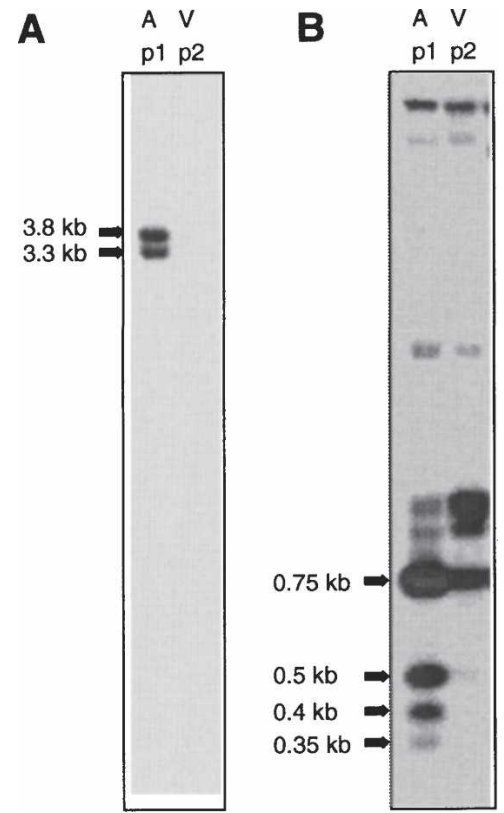

Figure 2. Genomic Southern blot analysis reveals polymorphism of two candidate TDFs in the parental strains 80029 (p1) and 88133 (p2) of a mapping population. The arrows indicate the polymorphic bands. The DNA was hybridized with probes derived from TDF3.1 (A) or TDF3.4 (B).
We conclude that the genetically identified Avr $3 b-A v r 10$ Avr11 locus on linkage group VIII is covered by BAC contig-I.

\section{The Avr3b-Avr10-Avr11 locus contains one full-length gene}

As shown by the intensity of the hybridization signals, contig-I contains multiple copies of TDF3.4. BAC20I24, however, is the only BAC that is confirmed to contain the ApoI restriction site giving rise to TDF3.4 and was, therefore, selected to clone a putative avirulence gene. Hybridization showed that BAC20I24 contains at least two copies of TDF3.4 located on two different BamHI fragments of 7 and $5 \mathrm{~kb}$, respectively. The 7-kb fragment was subcloned, and sequencing revealed a single ORF of $5871 \mathrm{bp}$. The 1.1-kb sequence upstream of the ORF contains a consensus for an oomycete transcription initiation site (Pieterse et al. 1994; McLeod et al. 2004), suggesting a 5' UTR of $547 \mathrm{bp}$. Analysis of other overlapping subclones of BAC20I24 showed that the 5-kb BamHI fragment represents a tandem repeat each carrying a TDF3.4 copy. One of the repeats has a $100 \%$ match with the TDF3.4 sequence and an ORF of $2877 \mathrm{bp}$ in the same frame as the ORF on the $7-\mathrm{kb}$ fragment ending with the same stop codon. There are, however, several SNPs when compared with the ORF on the 7-kb fragment and also several in frame stop codons upstream of TDF3.4. Downstream from the stop codon sequence identity continues for at least $400 \mathrm{bp}$. Further sequencing of the 3' UTR on the 5-kb fragment revealed a sequence identical to TDF3.1 followed by a putative polyadenylation site, 1029 bp downstream from the stop codon. To distinguish the different copies we named the full-length copy on the 7-kb BamHI fragment pi3.4F (Phytophthora infestans $\underline{3.4}$ Full length) and the second copy that lacks the $\mathrm{N}$ terminus, pi3.4T (Phytophthora infestans $\underline{3.4}$ Truncated). Other copies are named pi3.4 unless mentioned otherwise.

Of the six BAC contigs that hybridize to TDF3.4, only BAC contig-I contains the full-length copy pi3.4F. Hybridization with a probe derived from the $5^{\prime}$ end of the ORF (Probe A, Fig. 3B) showed that all contig-I BACs were positive except the two multicopy BACs, BAC34G01 and BAC40D02 (Supplemental Table $\mathrm{S} 1)$. Because of the diagnostic ApoI site, we know that pi3.4F on BAC20I24 cosegregates with the avirulence phenotype and we gave this particular copy a suffix A for Avirulence-associated: pi3. $4 F^{A}$. The allelic copy pi3. $4 F^{V}$ is derived from the virulent haplotype, and sequencing of subclones from BAC15E9 revealed an ORF of exactly the same length as in pi3. $4 F^{A}$. The promoter region and the first $4155 \mathrm{nt}$ of the ORF are exactly identical in pi3. $4 F^{A}$ and pi3. $4 F^{V}$ but in the last $1716 \mathrm{nt}$ there are SNPs, and immediately downstream from the stop codon the sequences diverge (Supplemental Fig. S1). pi3. $4 F^{V}$ is the only pi3.4 copy present on BAC15E9 and the only pi3.4 copy present at this locus in the virulent haplotype.

Multiple markers selected from three independent approaches are derived from gene pi3.4

When the sequences obtained from the Avr $3 b-A v r 10-A v r 11$ locus were compared with the $23 A v r$-associated TDFs selected by BSA (Guo et al. 2006), two more TDFs with homology with pi3.4 were found. TDF3.16 and TDF3.19 are identical to sequences in pi3.4F and pi3.4T with the exception of one SNP between TDF3.19 and pi3.4F. They were initially ignored because RT-PCR and/or cDNAAFLP analysis showed no clear segregation in the F1 progeny. pi3.4F should give rise to a large transcript $(\sim 6.5 \mathrm{~kb})$, and, as a 
Jiang et al.

A

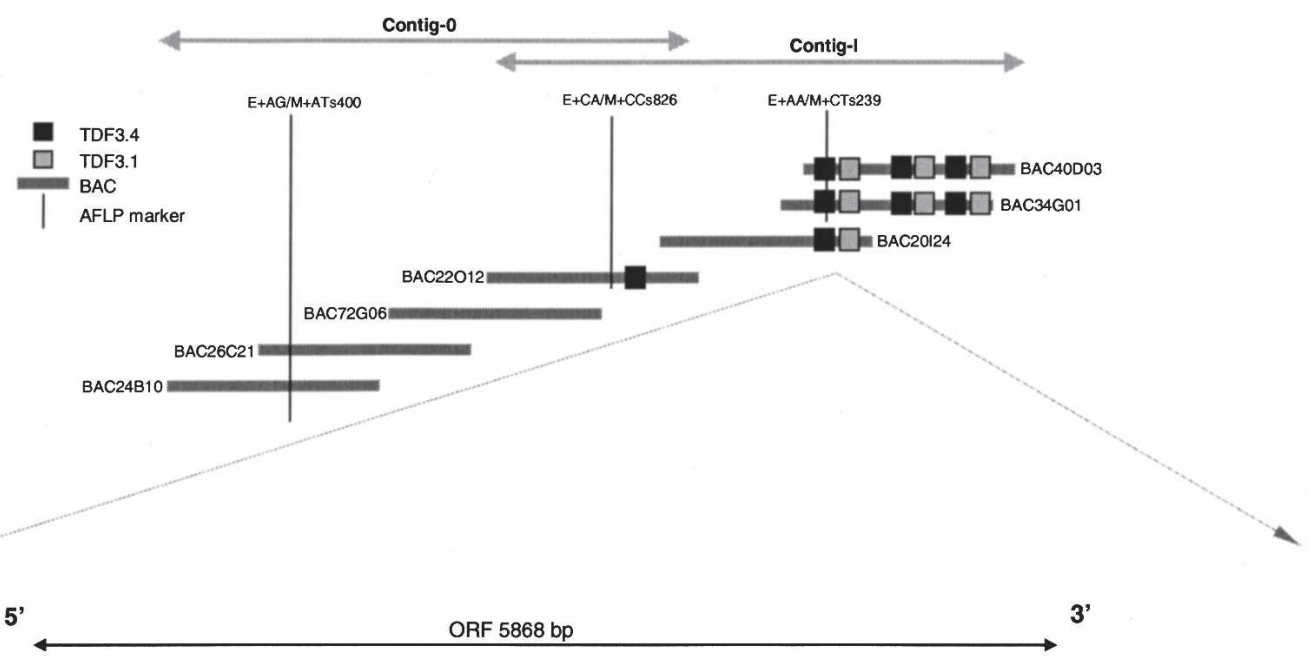

B

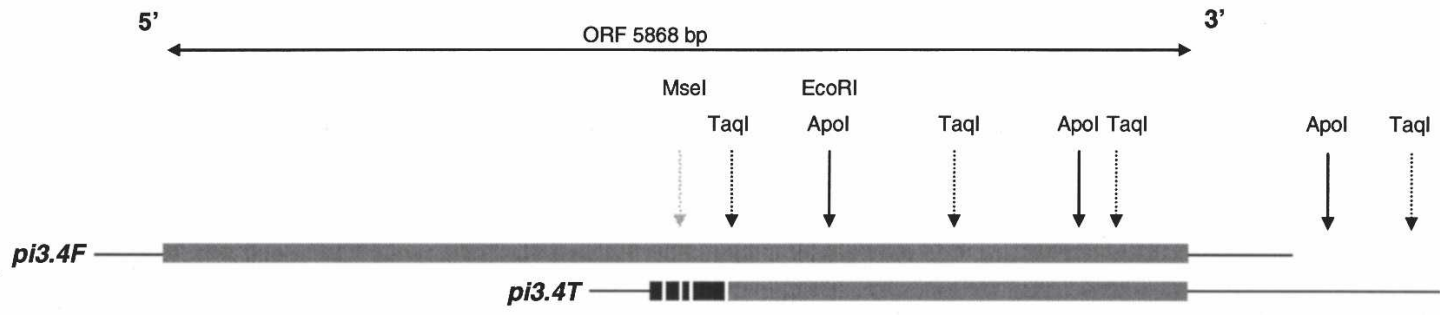

CDNA-AFLP

\begin{tabular}{lll}
\hline TDF3.4 TDF3.19 & TDF3.16 \\
\hline
\end{tabular}

TDF3.1

Genetic mapping

AFLP marker m1 1.2

BSA expression profiling

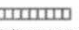

Pi003481

\begin{tabular}{|c|c|c|c|c|}
\hline Array-CGH & Pi014715 & Pi003481 & Pi015633 & Pi007841 \\
\hline Probes & & & & \\
\hline
\end{tabular}

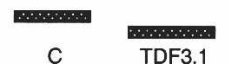

Figure 3. The Avr3b-Avr10-Avr11 locus on Linkage Group VIII. (A) BAC contigs across the Avr3b-Avr10-Avr11 locus. Contig-0 is the BAC contig previously identified by Whisson et al. (2001). (B) Multiple markers resulting from independent approaches (as listed on the left side) are derived from pi3.4. $\mathrm{m} 1.2$ is the cloned AFLP marker E+AA/M+CTs239. The sizes of BACs, genes, and markers are not drawn on scale.

result, multiple TDFs can be generated from the same gene. The four TDFs can also be matched to pi3.4F and pi3.4T based on the sites of the restriction enzymes used for cDNA-AFLP (Fig. 3B).

To find additional Avr-associated transcriptome markers, a second BSA expression profiling strategy was performed. The pooling strategy was similar to that used for cDNA-AFLP analysis (Guo et al. 2006; Supplemental Table S2), and pooled RNA samples derived from germinating cysts were used as probes on a custom designed Phytophthora GeneChip. Array sequences with more than twofold higher expression in avirulent pools as compared with virulent pools were selected as Avr candidates. Among 18,256 array sequences, three candidates were found of which one is derived from pi3.4. The sequence of pi003481 (472 bp) has one SNP when aligned with the pi3.4F $F^{A}$. The other two candidates either failed to give the expected polymorphism with RT-
PCR or did not cosegregate with the AVR3b-AVR10-AVR11 phenotype and were not pursued further (data not shown).

Sequence comparison of AFLP markers linked to Avr $3 b-$ Avr10-Avr11 and the TDFs showed that the 154-bp sequence of TDF3.4 is contained within the 239-bp sequence of AFLP marker $\mathrm{E}+\mathrm{AA} / \mathrm{M}+\mathrm{CTs} 239$ (clone m1.2). The polymorphism at the EcoRI site in the genomic DNA that gave rise to a marker on the genetic map overlaps with the ApoI site that forms the basis of an expression profiling marker.

In conclusion, one AFLP marker selected by genetic linkage mapping, four TDFs selected by cDNA-AFLP analysis, and one array sequence selected by the GeneChip expression array (Table 1) all landed in a relatively small region of $<10 \mathrm{~kb}$. Thus six candidate sequences obtained by three independent approaches are derived from gene pi3.4 (Fig. 3B). 
Modular diversity at a Phytophthora avirulence locus

Table 1. Multiple markers resulting from BSA expression profiling, genetic mapping, and array-CGH are localized in pi3.4

\begin{tabular}{|c|c|c|c|c|c|c|}
\hline Markers & Type of fragment & AFLP codes & $\begin{array}{l}\text { Size } \\
\text { (bp) }\end{array}$ & Selection criteria & $\begin{array}{l}\text { Confirmation } \\
\text { by RT-PCR }\end{array}$ & Aligns to \\
\hline TDF3.1 & Cloned cDNA-AFLP fragment & $\mathrm{A}+\mathrm{AG} / \mathrm{T}+\mathrm{ACs} 154$ & 154 & Differential expression in AVR strains & $x$ & $\begin{array}{l}\text { 3' UTR of } \\
\text { pi3.4T }\end{array}$ \\
\hline TDF3.16 & Cloned cDNA-AFLP fragment & $\mathrm{A}+\mathrm{GG} / \mathrm{T}+\mathrm{CCs} 85$ & 85 & Differential expression in AVR pools & & ORF \\
\hline TDF3.19 & Cloned cDNA-AFLP fragment & $\mathrm{A}+\mathrm{GT} / \mathrm{T}+\mathrm{TAs} 169$ & 169 & Differential expression in AVR pools & & ORF \\
\hline TDF3.4 & Cloned cDNA-AFLP fragment & $\mathrm{A}+\mathrm{AA} / \mathrm{T}+\mathrm{AGs} 158$ & 158 & Differential expression in AVR strains & $x$ & ORF \\
\hline $\mathrm{m} 1.2$ & Cloned AFLP fragment & $\mathrm{E}+\mathrm{AA} / \mathrm{M}+\mathrm{CTs} 239$ & 239 & Cosegregation with AVR phenotypes & & ORF \\
\hline PI003481 & EST-derived GeneChip array clone & - & 472 & $\begin{array}{l}\text { Differential expression in AVR strains and } \\
\text { increased copy number in AVR strains }\end{array}$ & & ORF \\
\hline PI007841 & EST-derived GeneChip array clone & - & 344 & Increased copy number in AVR strains & & ORF \\
\hline PI014715 & EST-derived GeneChip array clone & - & 1358 & Increased copy number in AVR strains & & ORF \\
\hline PI015633 & EST-derived GeneChip array clone & - & 191 & Increased copy number in AVR strains & & ORF \\
\hline
\end{tabular}

\section{The hemizygous Avr3b-Avr10-Avr11 locus contains numerous pi3.4 repeats}

The Avr3b-Avr10-Avr11 locus was proposed to be located in a hemizygous region because all linked AFLP markers were in coupling phase with avirulence while markers in repulsion phase were never found (van der Lee et al. 2001a). Moreover, m5.1, a cloned fragment of AFLP marker $\mathrm{E}+\mathrm{AG} / \mathrm{M}+\mathrm{ATs} 400$ located in contig-0 (Fig. 3A), is absent in the virulent parent and progeny of the cross 71 mapping population (van der Lee et al. 2001b). Similarly, in this study we showed that TDF3.1, located in the 3' UTR of pi3.4T, is unique for the avirulent parent, demonstrating that this truncated copy of pi3.4 is absent in the virulent parent (Fig. $3 \mathrm{~B})$. These data confirm that the Avr3b-Avr10-Avr11 locus is hemizygous with deletions in the virulent allele.

On the other hand, the avirulent allele seems to comprise specific repeats. Fragments $\mathrm{m} 1.2$ and $\mathrm{m} 7.1$, both derived from Avr3b-Avr10-Avr11-linked AFLP markers, showed stronger hybridization to genomic DNA of the avirulent parent 80029 and avirulent progeny than to that of virulent parent and progeny (van der Lee et al. 2001b). Also TDF3.4, which is part of m1.2, showed strong hybridization to several genomic DNA fragments in the avirulent parent (Fig. 2B) and progeny. This high intensity of hybridization indicates the presence of pi3.4 repeats in AVR3b-AVR10-AVR11 strains. Since two contig-I BACs appear to contain multiple copies of pi3.4, we conclude that the repeats are located at the Avr3b-Avr10-Avr11 locus. BAC34G01 and BAC40D03 both have an insert size of $160 \mathrm{~kb}$ and largely overlap. Presence of repeats was demonstrated by hybridization and restriction digestion of BAC DNA. Repeat-like patterns with few but very intense bands were observed and the repeat unit length was estimated at $7 \mathrm{~kb}$. With the notion that the full-length ORF of pi3. $4 F$ is nearly $6 \mathrm{~kb}$, we anticipate that many truncated or fragmented copies of pi3.4 are located on BAC34G01 and BAC40D03 and, hitherto, at the genetic locus covered by these BACs.

To investigate which part of pi3.4 is amplified, probes spanning different parts of the gene were designed (Fig. 3B) and hybridized to BglII-digested DNA of BAC34G01 and BAC40D03. With probe A located in the $5^{\prime}$ end of the pi3.4F ORF no hybridization was found, but with probe B located more to the $3^{\prime}$ end there was a very strong hybridizing fragment of $2.3 \mathrm{~kb}$, and the signal was around 50-fold higher than that of other pi3.4 containing BACs. Also with probe $\mathrm{C}$, located in the immediate 3' UTR of pi3.4T, and with TDF3.1 a strong signal was obtained. These results show that at the Avr3b-Avr10-Avr11 locus truncated copies of pi3.4 are amplified. We refer to these copies as pi3.4A ( Phytophthora infestans $\underline{3.4}$ Amplified).

\section{Amplification identified by array-CGH}

To investigate the relationship between gene amplification and avirulence phenotype, we used comparative genomic hybridization (CGH). CGH has traditionally been used to investigate gene amplifications or deletions at a genome-wide scale using metaphase chromosomes as targets (Suijkerbuijk et al. 1994). More recently array-based CGH methods were developed that allow genome-wide screening of genomic copy number changes at a much higher resolution, and array-CGH is now commonly used to detect genomic aberrations in cancer or to identify disease genes in humans (Vissers et al. 2005). Arrays of genomic fragments or oligonucleotide microarrays are hybridized with total genomic DNA isolated from different individuals or tissues, and differences in hybridization intensity reveal which sequences are amplified or deleted (Lucito et al. 2003).

We hybridized the custom designed Phytophthora GeneChip with probes derived from genomic DNA isolated from eight $P$. infestans strains, including six $\mathrm{F} 1$ progeny from the mapping population with different AVR phenotypes. Array-GCH revealed that, out of 18,256 array sequences, eight sequences representing six genes have large copy number changes (standard deviation $>0.5$ ) (Fig. 4A). As the selection criteria were rather stringent these six loci are expected to have drastic variations in copy numbers. Interestingly, two of the amplified loci could be correlated to AVR phenotypes (Fig. 4A). Amplification of two array sequences, pi003481 and pi014715, was observed in AVR3bAVR10-AVR11 strains. Both array sequences have homology with pi3.4, demonstrating that also an unbiased approach reveals a drastic amplification of pi3.4 in avirulent strains. The second amplification was observed with array sequence pi008646 and occurs in strains having an AVR2 phenotype. This sequence has no homology with any known gene and no homolog in $P$. sojae or P. ramorum. Moreover, pi008646 did not show an AVR2associated expression pattern in the BSA expression profiling experiment using the same GeneChip and, as yet, the significance of this amplification and the relation with Avr2 are not clear.

In addition to pi003481 and pi014715, the GeneChip contains two other sequences with sequence homology with pi3.4 (pi007841 and pi015633). All four sequences show 97\%-99\% similarity to pi3. $4 F^{A}$ (Table 2). They are either derived from different pi3.4 copies or they represent polymorphisms between T30-4 and 88069, the strain from which most of the array sequences are deduced. The behavior of all four pi3.4 sequences in the array-CGH is similar with three of the four showing a more than twofold increase in intensity in avirulent versus virulent strains (Fig. 4B). The lower increase seen with pi007841 is possi- 
A

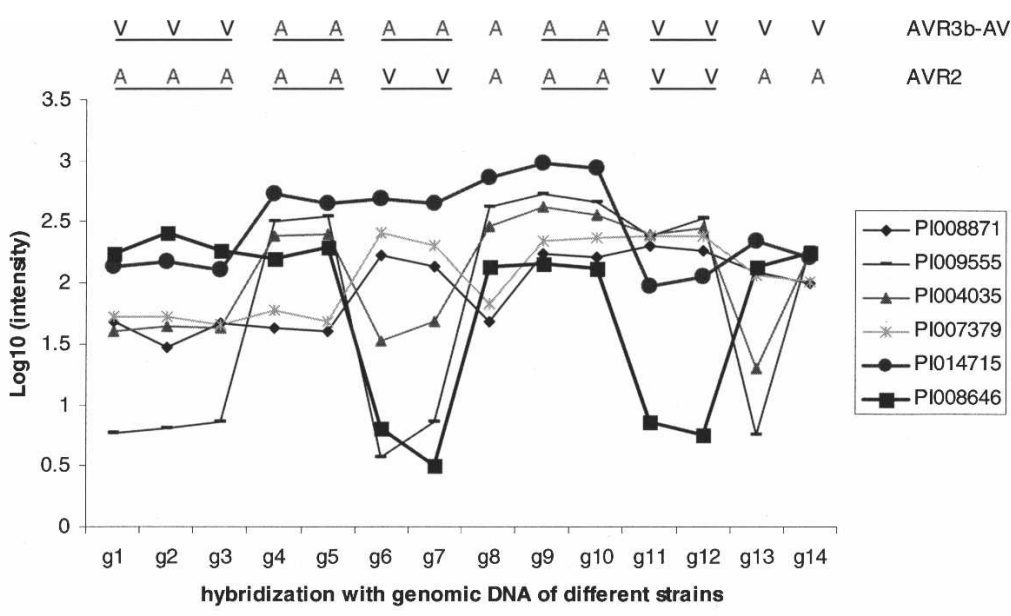

B

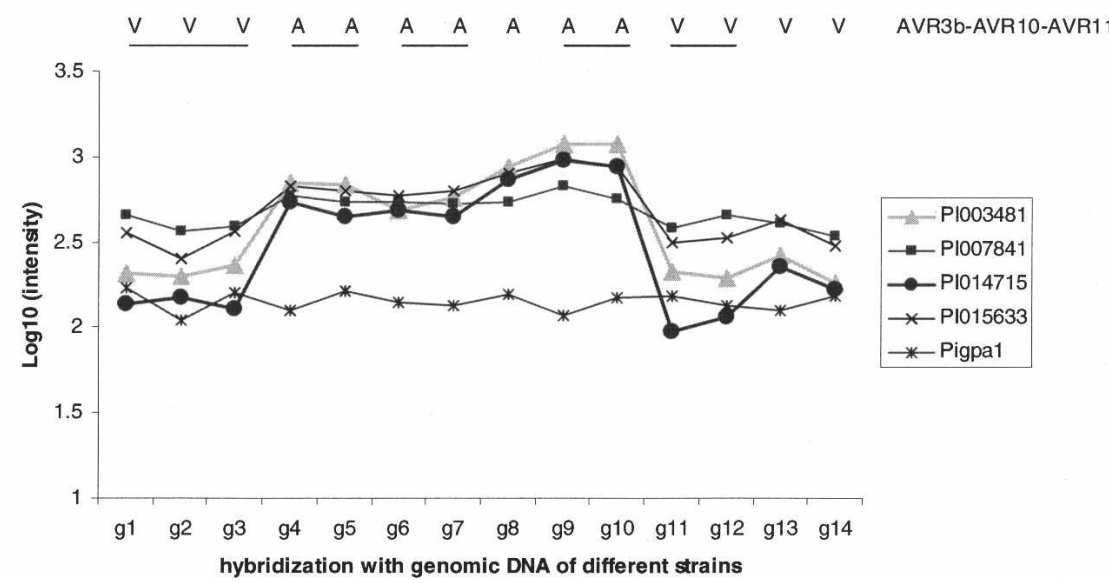

Figure 4. Array-CGH reveals copy number variation (CNV). The Phytophthora GeneChip was hybridized with genomic DNA derived from isolates T30-2 (g1, g2, g3), T15-5 (g4, g5), D12-17 (g6, g7), T30-3 (g8), T20-4 (g9, g10), D12-6 (g11, g12), 90128 (g13), and 88069 (g14). The phenotypes of the strains are indicated by $\mathrm{V}$ (virulent) or $\mathrm{A}$ (avirulent). Samples derived from the same strain are underlined. The $y$-axis shows the log10 of the hybridization intensity. $(A)$ Eight array sequences representing six genes show CNV (standard deviation $>0.5$ ). Pi003481 and Pi004035 gave similar patterns as Pi014715 and Pi001829 (not shown here) respectively, and each of these pairs is derived from the same gene. Pi014715 and Pi008646 show correlations with avirulence phenotypes (AVR3b-AVR10 AVR11 and AVR2, respectively), whereas the other four show no correlation with any known phenotype. For further details see Supplemental Table S3. (B) Four array sequences derived from pi3.4 show an AVR3b-AVR10-AVR11-correlated CNV. The array sequence representing the single-copy gene Pigpa1 was plotted as control.

bly due to the fact that only three out of 13 oligonucleotides on the GeneChip representing pi007841 are identical to the pi3.4F sequence; the other 10 have SNPs or gaps (Table 2). The reason that pi007841 and pi015633 did not show up in the unbiased screening is the difference in stringency.

Since the four identified array sequences are the only ones out of a total of 18,256 array sequences that show distinct AVR3b-AVR10-AVR11 correlated patterns, the gene amplification associated with AVR3b-AVR10-AVR11 seems to be specific for pi3.4. One should bear in mind, however, that this Phytophthora GeneChip was not designed as a genome-wide array. The array oligonucleotides are based on a unigene set deduced from over 75,757 ESTs from different tissues and developmental stages (Randall et al. 2005). It is not known how many more sequences on the GeneChip, if any, correspond to this particular region on
Linkage Group VIII and it is therefore not possible to delineate the borders of the amplification.

\section{pi3.4 amplification in $P$. infestans field isolates is associated with AVR3b- AVR10-AVR11 phenotypes}

The array-CGH experiment included two $P$. infestans field isolates, 88069 and 90128 , that are both virulent on $R 3 b$, $R 10$, and R11 plants. Similar to 88133 (i.e., the virulent parent of cross 71), 88069 and 90128 show no amplification of pi3.4 (Fig. 4A). To further analyze the association between pi3.4 and the AVR3b-AVR10-AVR11 phenotype in field isolates, the pi3.4-derived AFLP marker E+AA/M+CTs239 was analyzed in 29 field isolates collected in the Netherlands between 1980 and 1991. This population has highly diverse avirulence phenotypes and comprises many different DNA fingerprint genotypes (Drenth et al. 1994). The presence of E+AA/ $\mathrm{M}+\mathrm{CTs} 239$ correlates with the AVR3b phenotype in five isolates including 80029 , the avirulent parent of the mapping population, whereas 24 isolates virulent on $R 3 b$ plants (race $3 \mathrm{~b}$ ) lack the AFLP marker. Also four other AFLP markers previously mapped at the $A v r 3 b-$ Avr10-Avr11 locus and in the contig-0 region were analyzed, but none of these showed this strong correlation (Supplemental Table S4). This demonstrates that also in field isolates a polymorphism that maps in pi3.4 correlates with the AVR3b phenotype. The five AVR3b isolates are also avirulent on $R 10$ and $R 11$ plants. However, from the 24 race $3 \mathrm{~b}$ isolates seven are avirulent on either $R 10$ or $R 11$. This suggests that not in all cases Avr3b, Avr10, and Avr11 are as closely linked as in the mapping population. It should be noted, however, that symptoms on $R 10$ and $R 11$ plants are in general less severe than symptoms on $R 3 b$ plants (van der Lee et al. 2001a) and, therefore, phenotypic scoring for AVR10 and AVR11 may not be as accurate as for AVR3b.

To investigate whether pi3.4 is amplified in the Dutch field isolates, a set of 17 isolates with different AVR phenotypes was subjected to genomic Southern blot analysis. Hybridization with probe A resulted in multiple hybridizing fragments in all isolates with some polymorphisms, but there is no correlation with the avirulence phenotype (Fig. 5). Two strongly hybridizing fragments of 0.8 and $0.9 \mathrm{~kb}$ are present in all isolates and comigrate with fragments in BAC20I24. Probe B also hybridizes to multiple polymorphic fragments. Polymorphic bands of $0.4 \mathrm{~kb}$ and 0.35 $\mathrm{kb}$ are present in avirulent isolates but absent in virulent isolates. A 0.5 - and $0.75-\mathrm{kb}$ band shows a higher intensity in avirulent isolates than in virulent ones. Probe $\mathrm{C}$ and TDF3.1 both hybridize 
Modular diversity at a Phytophthora avirulence locus

Table 2. Ratios of hybridization levels in avirulent and virulent strains

\begin{tabular}{|c|c|c|c|c|c|c|}
\hline $\begin{array}{l}\text { Code of } \\
\text { the array } \\
\text { sequence }\end{array}$ & $\begin{array}{l}\text { Size of the } \\
\text { sequence } \\
\text { (bp) }\end{array}$ & $\begin{array}{c}\text { Polymorphisms } \\
\text { compared with } \\
\text { pi3.4F }\end{array}$ & $\begin{array}{c}\text { Polymorphisms } \\
\text { compared with } \\
\text { pi3.4F }\end{array}$ & $\begin{array}{l}\text { Number of oligos } \\
\text { identical to pi3.4F } \\
\text { or with mismatch }{ }^{\mathrm{a}, \mathrm{b}}\end{array}$ & $\begin{array}{l}\text { Number of oligos } \\
\text { identical to pi3.4Fv } \\
\text { or with mismatch a,b }\end{array}$ & $\begin{array}{c}\text { Avirulent/virulent } \\
\text { strains } \\
\text { (array-CGH) }\end{array}$ \\
\hline $\mathrm{PI003481^{c }}$ & 472 & 1 SNPs & 2 SNPs & $12 / 1$ & $13 / 0$ & 3.8 \\
\hline PI014715 & 1358 & 27 SNPs & 27 SNPs & $10 / 3$ & $9 / 4$ & 4.4 \\
\hline PI015633 & 191 & 6 SNPs & 0 SNPs & $7 / 6$ & $13 / 0$ & 2.2 \\
\hline PI007841 & 344 & $\begin{array}{l}8 \text { SNPs } \\
26 \text { bp gap, } 27 \text { bp } \\
\text { cannot be aligned }\end{array}$ & $\begin{array}{l}8 \text { SNPs } \\
26 \text { bp gap, } 27 \text { bp } \\
\text { cannot be aligned }\end{array}$ & $3 / 10$ & 2/12 & 1.4 \\
\hline $\begin{array}{l}\text { PI000084 } \\
\quad(\text { Pigpa 1) })^{\mathrm{d}}\end{array}$ & 254 & $0^{\mathrm{e}}$ & & & & 1.0 \\
\hline
\end{tabular}

For array-GCH, the custom-designed Phytophthora GeneChip was used. The first four array sequences listed are derived from pi3.4.

aFor each array sequence, a set of 13 oligos (25 bp) was designed and synthesized on the array.

${ }^{b}$ Mismatch oligos contain 1-15 mismatching nucleotides as compared with pi3.4F ${ }^{A}$ or pi3.4FV.

'PI003481 was also selected by BSA expression analysis on the Phytophthora GeneChip.

${ }^{\mathrm{d}} \mathrm{PI000084}$ represents the single-copy gene Pigpa1.

eCompared with Pigpa 1.

to a 3.8- and 3.3-kb fragment lacking in virulent isolates. These results show that, also in these field isolates, a pi3.4 amplification is associated with avirulence and that the presence of pi3.4T and pi3.4A is diagnostic for the AVR3b-AVR10-AVR11 phenotype.

\section{pi3. $4 F$ and pi3.4T encode proteins that resemble transcription} factors

At the Avr3b-Avr10-Avr11 locus, we distinguish three different pi3.4 genes: the full-length pi3.4F $F^{A}$, the truncated pi3.4T, and the amplified pi3.4A. The virulent haplotype also contains a fulllength pi3.4 copy at this locus, pi3. $4 F^{V}$, but lacks the truncated and amplified copies. Both pi3. $4 F^{A}$ and pi3. $4 F^{V}$ contain one intact continuous ORF encoding a protein of 1956 amino acids with several typical domains and motifs (Fig. 6). The N-terminal part contains a WD40 domain and at the $\mathrm{C}$ terminus there is a nuclear localization signal (NLS) followed by an acidic domain comprised of nearly only $\mathrm{D}$ and $\mathrm{E}$ residues and a leucine zipper. The truncated copy, pi3.4T, has an ORF coding for a 959-amino acid protein, but with several potential start codons downstream from the first ATG. The exact size of the Pi3.4T protein is therefore unknown, but, irrespective of the start codon, Pi3.4T includes the NLS, the acidic domain, and the leucine zipper. Two Phytophthora species that have been fully sequenced (http://genome.jgi-psf.org/ and http:// phytophthora.vbi.vt.edu/) contain, each of them, one highly similar homolog of pi3. $4 F$ but no truncated copies. At the protein level the homologs in Phytophthora sojae (ps3.4) and Phytophthora ramorum (pr3.4) show $77 \%$ similarity to Pi3.4F, whereas the similarity between Ps3.4 and Pr3.4 is 81\% (Supplemental Fig. S1). There are no homologs known in other species, except in dog (Canis familiaris), where one protein (XP_535743) is predicted with a similar domain organization. The identity in the N-terminal part is $30 \%(252 / 838)$ and in the C-terminal part 26\% (264/ 1002). The function of Pi3.4 is unknown, but the combination of a NLS, an acidic domain, and a leucine zipper often occurs in transcription factors.

\section{Modular diversity at the Avr3b-Avr10-Avr11 locus results in mosaic structures}

pi3. $4 F^{A}$ and pi3. $4 F^{V}$ show a very unequal distribution of polymorphism. The first $4155 \mathrm{nt}$ (region A and B in Fig. 6) are identical but within the last $1716 \mathrm{nt}$ (region C) there are 30 SNPs causing 10 amino acid changes (Supplemental Fig. S1). The distribution of SNPs between pi3.4F $F^{A}$ and pi3.4T, on the one hand, and pi3. $4 F^{V}$ and pi.3.4T, on the other hand, is remarkable. In region B pi3.4T shows 35 SNPs with pi3.4F resulting in six amino acids changes. However, in region $\mathrm{C}$ pi3.4T has only two SNPs with pi3. $4 F^{A}$ but 30 SNPs with pi3. $4 F^{V}$. Mosaic junctions seem to occur in the region surrounding the transition from region $\mathrm{B}$ to $\mathrm{C}$. We also analyzed four different pi3.4A copies located on the multicopy BACs. Sequence analysis of PCR fragments of 720 bp covering the NLS, the acidic domain, and the leucine zipper revealed
A

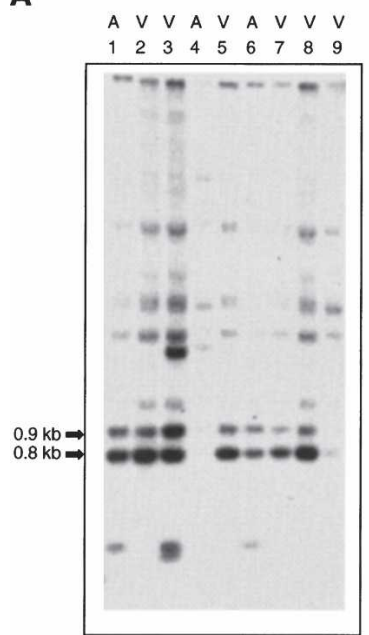

B

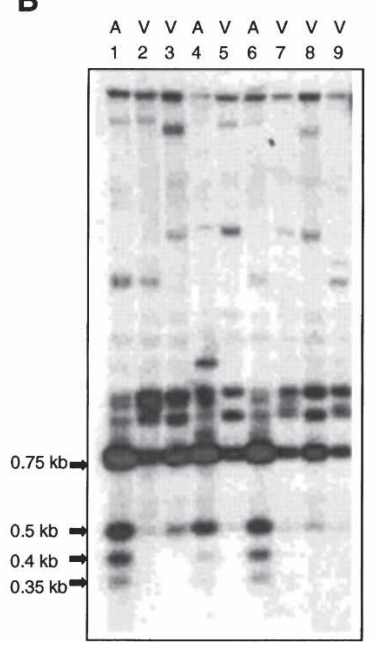

C

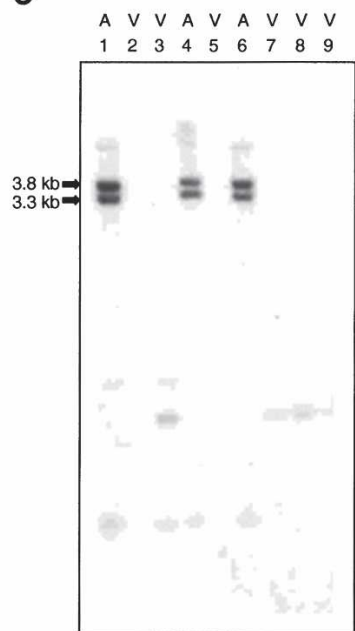

Figure 5. Genomic Southern blot analysis reveals a correlation between pi3.4 amplification and avirulence in field isolates. Genomic DNA derived from 80029 (1), 88133 (2), 84044 (3), 85005 (4), 85025 (5), 87001 (6), 87010 (7), 87177 (8), and 88175 (9) was digested with EcoR1 and Pstl and hybridized with probes derived from different parts of pi3.4 as shown in Figure 3B. Hybridization with probe $\mathrm{A}$ is shown in $(A), \mathrm{B}$ in $(B)$, and $\mathrm{C}$ in $(C)$. 


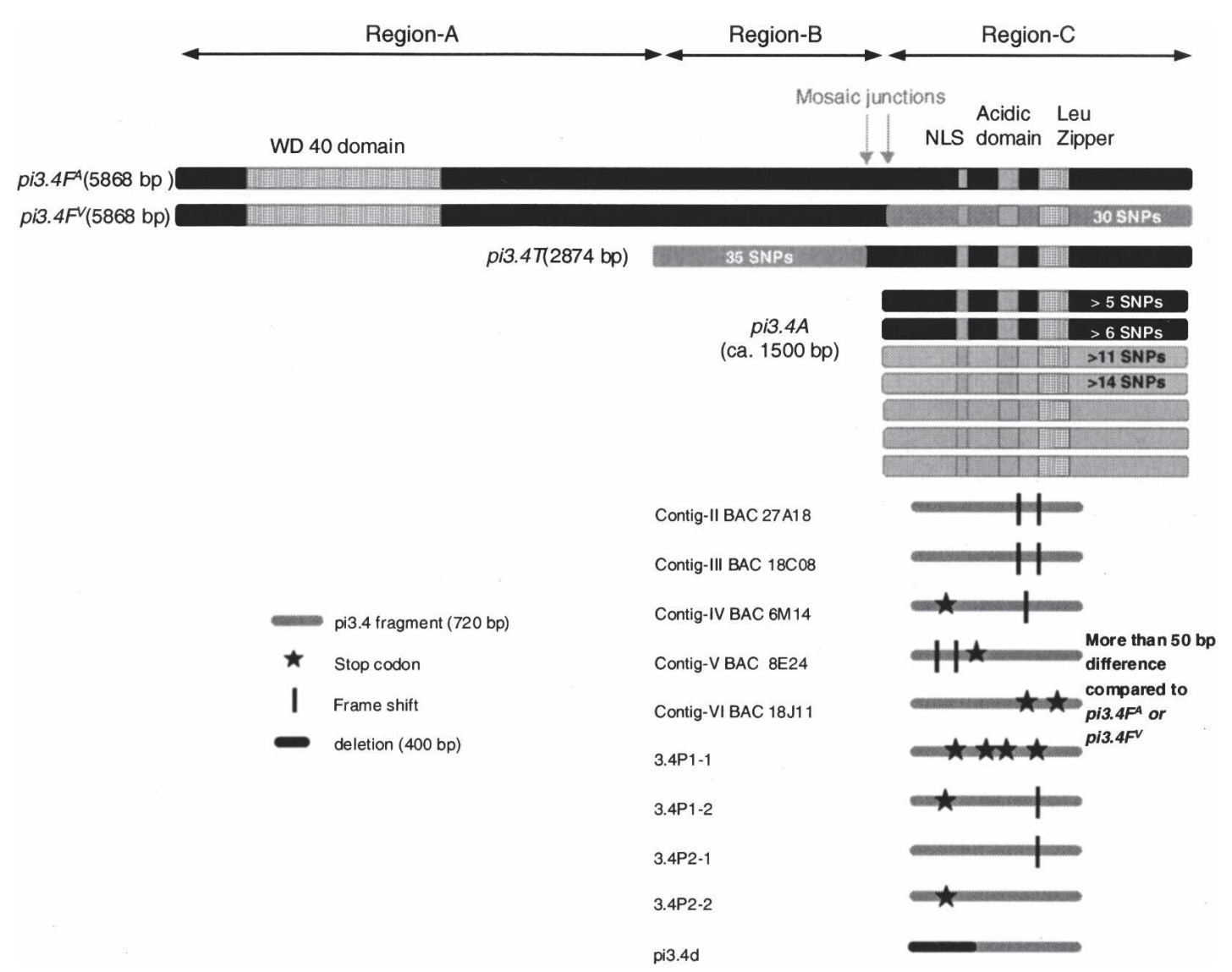

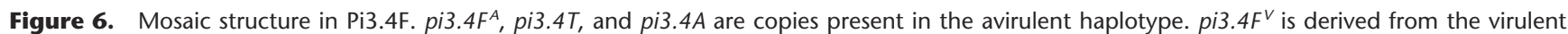
haplotype. The size of pi3.4A is estimated from transcript lengths. From various pi3.4A copies $720 \mathrm{bp}$ were sequenced, and the number of SNPs detected in these 720 bp fragments is indicated. Sequences derived from other loci carry frame shifts and stop codons, or have deletions. For alignments see Supplemental Figures S1, S2.

no stop codons or frame shifts. Two of the four showed closer sequence similarity to pi3.4F ${ }^{A}$ with five and six SNPs, and the other two to pi3.4F $F^{V}$ with 11 and 13 SNPs (Fig. 6). This suggests that the diversity in the pi3. $4 F^{V} 3^{\prime}$ end was generated from the amplified gene modules via unequal crossing-overs.

pi3.4F, pi3.4T, and pi3.4A are located on BAC contig-I but, in addition, several other pi3.4 copies are present elsewhere in the genome. To study the sequence diversity of pi3.4 within the genome, we analyzed pi3.4 fragments amplified from contig-II to VI BACs (Supplemental Table S1) and pi3.4 fragments obtained by PCR on genomic DNA. Sequence analysis showed that, apart from the intact pi3.4 copies present at the Avr $3 b-A v r 10-A v r 11$ locus, all the other copies are pseudo-genes carrying various frameshifts and stop-codon mutations or, in the case of pi3.4d, a large deletion of $400 \mathrm{bp}$ (Fig. 6).

Rearrangements in the $3.4 F$ region in $P$. infestans as compared with $P$. sojae and $P$. ramorum

$P$. infestans has multiple pi3.4 copies scattered in the genome and a pi3.4 amplification at the $A v r 3 b-A v r 10-A v r 11$ locus. In contrast, $P$. sojae and $P$. ramorum have only one homolog of pi3.4F each and no truncated copies. Genomic Southern blot analysis confirmed that in P. sojae, P. ramorum, and several other Phytophthora species 3.4 is a single-copy gene (not shown).
Analysis of genomic regions in the vicinity of ps3.4 and pr3.4 revealed a high level of colinearity between $P$. sojae and $P$. ramorum (Fig. 7). A total of 30 orthologous gene pairs can be identified in a region covering $127 \mathrm{~kb}$ in $P$. sojae and $93 \mathrm{~kb}$ in $P$. ramorum. Only two genes in $P$. sojae and one in $P$. ramorum do not have orthologs in the syntenic region. The gene order is well conserved except for one reversal. The genes immediately flanking ps3.4 in $P$. sojae are conserved in $P$. ramorum. To investigate whether this colinearity also exists in $P$. infestans, we searched for the putative orthologs in $P$. infestans using the $P$. ramorum sequence of the 30 ortholog pairs. Among 18,256 sequences present on the Phytophthora GeneChip 20 homologs were assigned based on best BLAST hit with $E$-value $<1$ e- 30 and $>50 \%$ matching residues. None of the 20 array sequences, however, showed a gene amplification pattern similar to pi3.4 (Fig. 7). For a more direct approach we selected four $P$. infestans ESTs that are the homologs of four genes located in the near vicinity of ps3.4 and pr3.4 (Fig. 7; Supplemental Table S5) and used these as probes to screen the BACs containing pi3.4 copies; however, none of the four ESTs hybridized. The BAC contigs cover around 100-150 kb each and the contig-0/contig-I region is even larger. In $P$. ramorum these four genes are located within a 12 -kb region surrounding pr3.4. Even when we take into account that the genome of $P$. infestans is less gene dense than that of $P$. ramorum (Jiang et al. 2005), the homologs should still be present on the BAC contigs. In the near future, when the genome sequence of $P$. infestans is 


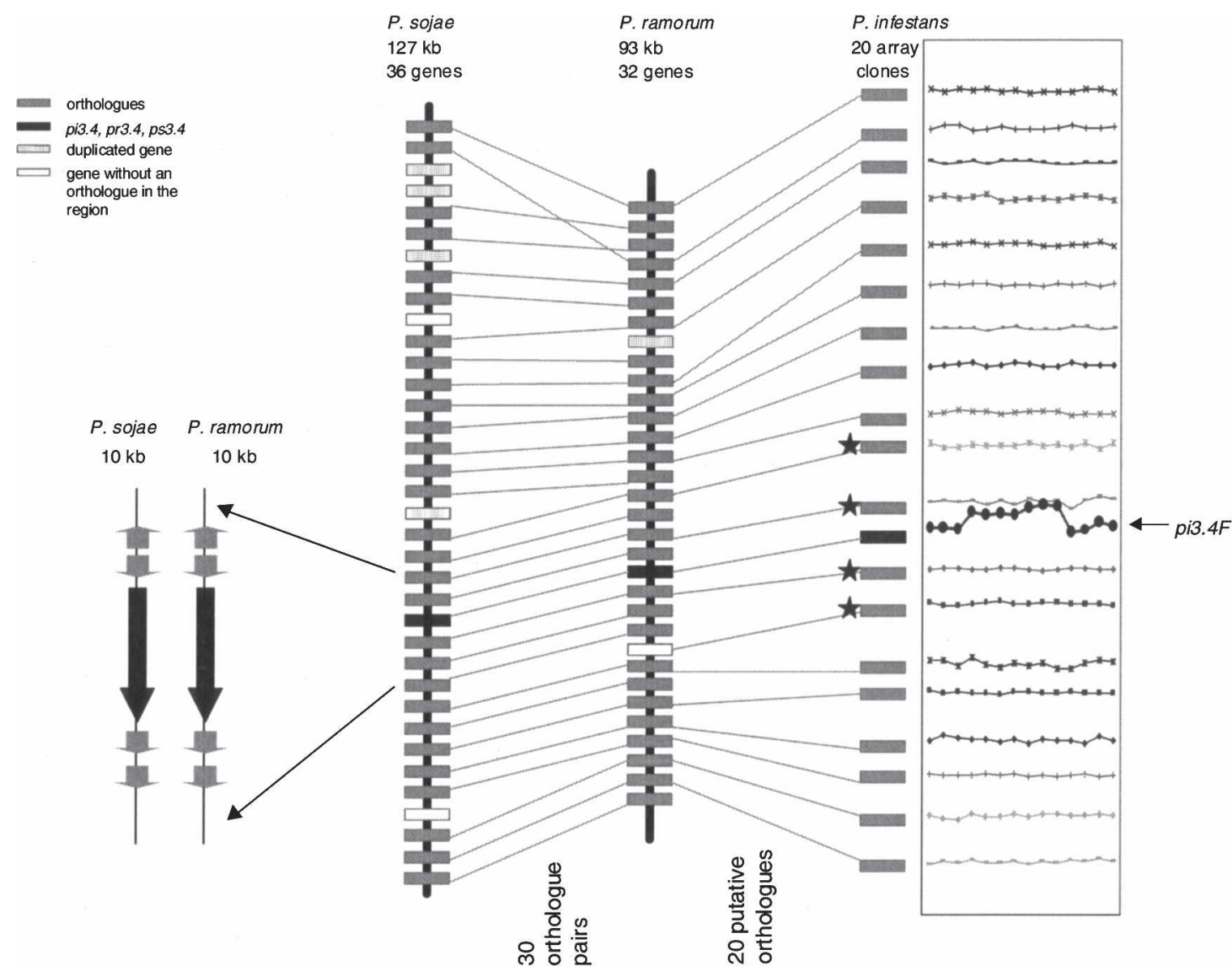

Figure 7. Synteny between $P$. sojae and $P$. ramorum in genomic regions containing the pi3.4F homolog. pr 3.4 and ps 3.4 are single-copy genes (indicated in black). Among 18,256 P. infestans array sequences, 20 homologs of the 30 ortholog pairs are found. Stars indicate the four ESTs used for screening the BAC contig. On the right, the log10 of the intensity of the array- $\mathrm{CGH}$ is plotted next to the homolog in $P$. infestans.

assembled, the position of the four ESTs in relation to the six pi.4 loci can be investigated. The results we have so far suggest lack of synteny in any of the six pi3.4 regions with the 3.4 regions in $P$. ramorum or $P$. sojae. There is, however, synteny between $P$. infestans, $P$. sojae, and P. ramorum in other regions (R.H.Y. Jiang, I. Sama, and F. Govers, unpubl.). The lack of synteny and the observation that pi3.4 has multiple truncated copies scattered over the genome suggest that the pi3.4 region has been translocated and is prone to amplification and reshuffling.

\section{Discussion}

\section{An avirulence locus with a regulatory gene}

We have successfully combined transcriptional profiling, genetic mapping, and array-CGH to physically map a complex avirulence locus in $P$. infestans that contains an amplified gene cluster with modular diversity in the amplified gene. Unlike most avirulence loci hitherto identified, the Avr3b-Avr10-Avr11 locus does not encode a typical secreted elicitor protein. Instead, it contains genes encoding proteins with a domain organization reminiscent of transcription factors. A full-length copy (pi3.4F) is present in the virulent as well as the avirulent haplotype, but the truncated copies (pi3.4T) are exclusively found in the avirulent haplotype (Fig. 8). Compared with full-length, truncated copies lack a
WD40 domain, a domain involved in protein-protein interactions but not essential for transcriptional activation. The amplified gene cluster is restricted to isolates with the AVR3b-AVR10AVR11 phenotype. Upon infection these isolates induce a hypersensitive response (HR) in potato lines carrying the $R 3 b, R 10$, and $R 11$ resistance genes, and, as a result, disease development is arrested. The fact that three avirulence genes map genetically at the same locus and that this locus contains a regulatory gene favor a model in which the Avr $3 b-A v r 10-A v r 11$ locus is responsible for regulating the expression of other genes. These target genes might encode secreted proteins that function as AVR factors in the gene-for-gene model and are recognized by the corresponding $R$ proteins. In the cross 71 mapping population $A v r 3 b$, Avr10, and Avr11 always cosegregate, and our model thus requires that in the parental lines the target genes are either homozygous or consist of two avirulent alleles. This also explains why the transcriptional profiling on this particular mapping population did not lead to $A v 3 b, A v r 10$, or $A v r 11$ candidates other than pi3.4.

To find support for this model we re-examined the results of Al-Kherb et al. (1995). Apart from our own studies, this is the only one including analyses on inheritance of Avr10 and Avr11 in $P$. infestans. In two crosses they found indications for a second locus being involved in determining the AVR10 phenotype, and this complies with our model. Unfortunately, the parents of the 
A

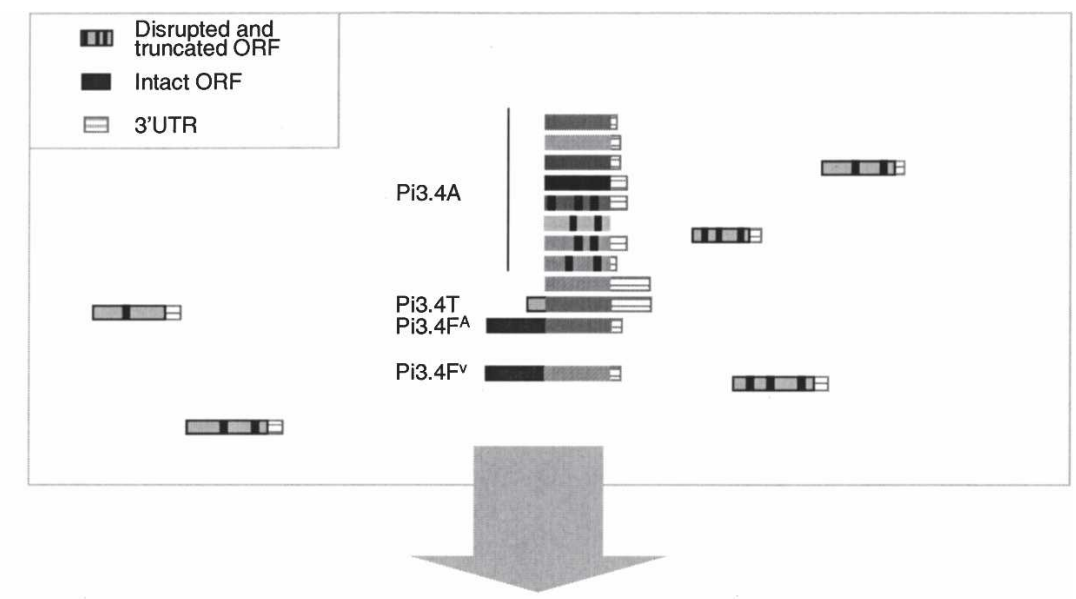

B

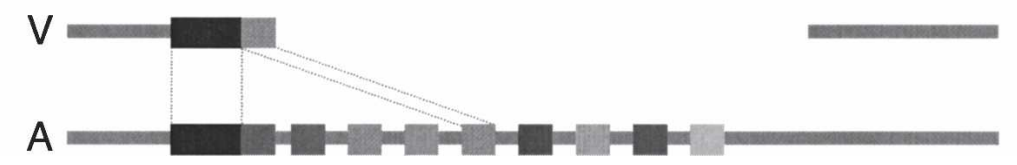

Figure 8. Modular diversity at the hemizygous Avr3b-Avr10-Avr11 locus. (A) P. infestans contains multiple copies of pi3.4 distributed over the genome. Most copies are pseudo-genes. The hemizygous Avr3b-Avr10-Avr11 locus contains numerous pi3.4 copies and is the only locus with a full-length copy (pi3.4F $\mathrm{F}^{A}$ ) and truncated copies with intact ORFs (pi3.4T and a subset of the pi3.4A copies). (B) Unequal crossing-over at the hemizygous Avr3b-Avr10-Avr11 locus. The pi3.4 amplification may serve as a source of modules for the assembly of novel full-length genes.

two crosses were both virulent on $R 11$ plants and, therefore, the inheritance of Avr11 could not be analyzed. Moreover, the R3 plants used by Al-Kherb et al. (1995) are from the Black differential set, that carry $R 3 a$ but lack $R 3 b$ (Huang et al. 2004). Hence, the AVR3 segregation is not informative for $A v r 3 b$. In four other crosses, Al-Kherb et al. (1995) found segregation of AVR10 and AVR11, but no indication for linkage between the two. In view of our model the lack of linkage can be explained when the regulatory locus in each of the parental lines of these four crosses is homozygous, while the target genes are heterozygous.

Additional support for a regulatory gene at an avirulence locus in oomycetes comes from studies on P. sojae Avr1b-1. This gene was isolated by positional cloning and encodes a secreted elicitor (Shan et al. 2004; Rehmany et al. 2005). Nevertheless, several isolates carrying an avirulent allele of $A v r 1 b-1$ remain virulent on plants carrying the resistance gene $R p s 1 b$, and this is due to the fact that $A v r 1 b-1$ is not transcribed. A second gene at the same locus, $A v r 1 b-2$, is required for accumulation of mRNA of $A v r 1 b-1$ and could encode a transcription factor. The $A v r 3 b-$ Avr10-Avr11 locus in P. infestans may also contain putative target genes, but so far we have no clue what other genes are located in the vicinity of the pi3.4 genes. Genome sequencing of $P$. infestans strain T30-4 is in progress at the Broad Institute and soon we will be able to scan the $P$. infestans genome for targets. Likely candidates are genes belonging to the RXLR family that encodes a diverse group of secreted proteins sharing a RXLR motif (Birch et al. 2006). RXLR is a hallmark of oomycete effector proteins. All four cultivar- or ecotype-specific oomycete $A v r$ genes identified to date have this motif, including $P$. sojae Avr1b-1, mentioned above (Shan et al. 2004), and P. infestans Avr3a (Armstrong et al. 2005). In plants carrying the corresponding $R$ gene, RXLR effectors elicit HR, but in the absence of the $R$ gene the RXLR proteins may be acting as virulence factors. Many proteins secreted by $P$. infestans contain an RXLR motif (Birch et al. 2006). One example is the protein encoded by $\mathrm{ipiO}$, a gene that is highly expressed in the periphery of expanding late blight lesions where hyphae invade plant cells (van West et al. 1998). This suggests that IPI-O has a role in pathogenicity and is supported by the observation that IPI-O binds to plant plasma membrane proteins and disrupts cell wall-plasma membrane adhesions (Senchou et al. 2004; Gouget et al. 2006). In bacteria several effector proteins are known to have a dual function in both virulence and avirulence (van't Slot and Knogge 2002) and many effector genes are transcriptionally controlled (Schell 2000; Jones 2005).

\section{The avirulence locus contains a full-length copy and truncated copies of pi3.4}

The fact that two different transcriptional profiling strategies, cDNA-AFLP and GeneChip expression arrays, gave rise to several markers associated with the Avr3b-Avr10-Avr11 locus suggests extreme expression differences between virulent and avirulent strains. Indeed high levels of mRNA of the truncated size and hybridizing to probes from the truncated copies were present in germinated cysts from avirulent strains but absent in virulent strains. In contrast, full-length transcripts were present in all strains but only at very low levels (R. Weide, R.H.Y. Jiang, and F. Govers, unpubl.). Presumably, both the full-length and truncated transcripts produce proteins, but without further analyses we do not know their function in determining the avirulent phenotype. With respect to the full-length copies, the localized polymorphism is remarkable and raises the possibility that Pi3.4F $\mathrm{F}^{\mathrm{A}}$ targets a different set of genes than $\mathrm{Pi} 3.4 \mathrm{~F}^{\mathrm{V}}$. The polymorphism, however, is restricted to the C-terminal part and hence the WD40 domain will not discriminate. Also the NLS, the acidic domain, and the leucine zipper are identical, suggesting interaction with the same DNA elements. It is therefore unlikely that pi3. $4 F^{A}$ is the gene that is responsible for the phenotype. The truncated copies with the intact ORFs are more attractive candidates since they are unique for avirulent strains. Their C-terminal parts are not very diverse from those in Pi3. $4 \mathrm{~F}^{\mathrm{A}}$ or Pi3. $4 \mathrm{~F}^{\mathrm{V}}$, suggesting they target the same genes. But why then are strains that carry only pi3. $4 F^{V}$ not capable of activating the target genes that confer avirulence on $R 3 b$, $R 10$, and $R 11$ plants? One possibility is that the WD40 domain in $\mathrm{Pi3}$.4F binds to a repressor or is itself an intramolecular repressor that prevents Pi3.4F to function as transcriptional activator. Another possibility is that the level of Pi3.4F is far too low to activate target genes. The gene amplification in avirulent strains may result in an enormous increase of the Pi3.4 protein and thus in a much more efficient activation of the target genes.

\section{The avirulence locus is a dynamic locus}

Physical mapping and sequence analyses of the Avr3b-Avr10 Avr11 locus revealed multiple copies of pi3.4 that contain intact ORFs but are slightly different in sequence. In all analyzed $P$. 
infestans isolates pi3.4 is a multigene family. In two distant Phytophthora species, $P$. sojae and $P$. ramorum, 3.4 is a single-copy gene. Southern blot hybridization showed that most Phytophthora species contain only a single copy of the 3.4 gene with the exception of Phytophthora mirabilis and Phytophthora ipomoea (P.J.I. van de Vondervoort and F. Govers, unpubl.). Since the latter two are closely related to $P$. infestans, we anticipate that the ancestral state of the 3.4 gene in the Phytophthora genus is a single-copy gene and that amplification occurred after divergence of the various clades. In $P$. infestans we found at least five copies outside the Avr $3 b-A v r 10-A v r 11$ locus, but none of these has an intact ORF. They all have different mutations, suggesting that, after the transition from a single-copy gene to a multigene family, there was no pressure for the various copies to remain functional (Fig. 6).

In $P$. sojae and $P$. ramorum the single-copy 3.4 gene is located on scaffolds that are largely syntenic for at least $100 \mathrm{~kb}$. In contrast, in the pi3. $4 F$ region in $P$. infestans the orthologs are absent and, apparently, in P. infestans (or its predecessor) the 3.4 gene moved from its original position to settle elsewhere in the genome. The fact that we observe amplification of truncated copies at one locus and spread of only truncated copies to other loci suggests that the initial translocation involved the full-length pi3.4 gene. Subsequent amplification by an unknown mechanism must have been the cause of the numerous truncated copies at the $A v r 3 b-A v r 10-A v r 11$ locus while erroneous recombination and unequal crossing-overs may have resulted in spread of truncated copies to other loci. It is also possible that the truncated copies moved independently to the other loci without a transfer at the $A v r 3 b-A v r 10-A v r 11$ locus. To reconstruct these events we need to analyze pi3.4 loci in more $P$. infestans isolates of different geographical origin and collected in different time periods. This study involved Dutch field isolates from the 1980s and 1990s. All AVR3b-AVR10-AVR11 isolates in this population have the amplification and the highest copy number at this locus found so far (estimated at 25). The Mexican isolate TV580 has a pi3.4 amplification at the same locus but the estimated copy number is lower than in the Dutch field isolates. Also US-1 isolates that were collected before the world-wide population displacement have variation in pi3.4 copy number (R. Weide and F. Govers, unpubl.). The finding that the pi3.4 amplification occurs in different populations raises the question if there is any advantage for $P$. infestans to have multiple copies of pi3.4. Obviously, for isolates that try to invade plants carrying $R 3 b, R 10$, or $R 11$, the amplification results in suicide and the only way to survive is to get rid of it. Alternatively, the pi3.4 amplification may result in massive production of regulators that control expression of effector genes. In infection assays on plants lacking $R$ genes we see no differences in pathogenicity between strains with and without the pi3.4 amplification, but we cannot exclude that in nature, isolates with the pi3.4 amplification behave differently. Under field conditions minor changes could have major effects. Late blight is a polycyclic disease, and a minimal increase in spore density or a slightly shorter infection cycle can speed up the development of the epidemics.

\section{Is the modular diversity responsible for variation?}

With array-CGH we found six loci in $P$. infestans that show CNV, including pi3.4. This analysis was limited to a few isolates and, therefore, we may have missed other loci with CNV. Nevertheless, we expect that the extreme CNV as seen at the pi3.4 locus is relatively rare. To date CNV has not been described for any other Phytophthora gene, despite the fact that Phytophthora has many multigene families. Most genes encoding secreted proteins belong to multigene families and often the family members are clustered in the genome (Jiang 2006). One example is M96, a family of mating-type specific genes that contains 22 tandemly arrayed copies at a single site (Cvitanich et al. 2006). In contrast to pi3.4, M96 is a family of tandemly repeated copies in all investigated Phytophthora species and occurs as such in both $P$. infestans haplotypes. Detailed analysis of the M96 gene family showed that it evolved via concerted evolution, but there are various other mechanisms by which gene families can evolve.

Gene amplification is one of the driving forces of genome evolution and it can greatly help to increase the level of certain gene products required for a specific developmental process (Tower 2004) or drug resistance (Donn et al. 1984; Field et al. 1988; Lengauer et al. 1998). To our knowledge, this study is the first reported case of a gene amplification associated with avirulence in a eukaryotic pathogen. Unequal crossing-over at the Avr $3 b-A v r 10-A v r 11$ locus may facilitate the change from avirulence to virulence, and, since the full-length pi3.4 copy on the virulent allele has a mosaic structure, it is most likely the result of such an unequal crossing-over event (Fig. 8). This is supported by the finding that some of the truncated copies from the avirulent haplotype have more sequence similarity to $p i 3.4 F^{V}$ than to pi3. $4 F^{A}$. On the other hand, the pi3.4 amplification may serve as a source of modules for the assembly of novel full-length genes, and, in turn, this molecular diversity may result in adaptive advantage to the pathogen. Emergence of novel genes by modular assembly from existing genes is well documented (Patthy 2003; Tordai et al. 2005). Classic examples are the immunoglobulin loci in vertebrates where module amplification and shuffling result in large molecular diversity at the protein level. The pi3.4 amplification makes the Avr $3 b-A v r 10-A v r 11$ locus an attractive locus to study the exact mechanism that is used by $P$. infestans to generate modular diversity and to investigate how pathogens can use modular diversity to adapt to their environment.

\section{Methods}

\section{P. infestans strains, nomenclature, and phenotypes}

The $P$. infestans strains are Dutch field isolates collected in the 1980s and 1990s. Previously two of these strains, 80029 and 88133 , were used to generate a mapping population, designated as cross 71 (Drenth et al. 1995; van der Lee et al. 1997). The F1 progeny strain T30-4 was used to construct a BAC library (Whisson et al. 2001). The nomenclature of genes, gene clusters, and phenotypes is according to van der Lee et al. (2001a) with one exception; Avr3 now has the suffix "b" to indicate that this $A v r$ gene elicits resistance on plants carrying $R 3 b$ and not $R 3 a$ (Huang et al. 2004). Consequently, an avirulent and virulent phenotype on $R 3 b$ plants is indicated by AVR3b and avr3b, respectively. For this study the phenotype on plants carrying $R 3 b, R 10$, and $R 11$ is relevant. Strains 80029 and T30-4 are avirulent on these plants and thus have the AVR3b-AVR10-AVR11 phenotype, whereas 88133 is virulent and has the avr3b-avr10-avr11 phenotype.

\section{Nucleic acids manipulation and Southern blot analysis}

Genomic $P$. infestans DNA was isolated according to van West et al. (1998). Isolation of RNA from mycelia, sporangia, zoospores, and germinating cysts was performed as described by van West et al. (1998). Southern blot analysis was conducted as described by 
Sambrook and Russell (2001). Hybridization probes cover different parts of the pi3.4F gene and included TDF3.1 and TDF3.4 (Fig. 3B). Probe A is the $5^{\prime}$ ORF probe: a 556-bp PCR fragment amplified from BAC20I24 with the primer pair pi3.4F5f (GTGCGCCC ACTGTCCAACTGGG) and pi3.4F5r (CCGACAGACAGCGGC TTCCTCG) and covering the region starting $0.12 \mathrm{~kb}$ downstream from the start codon. Probe B is the 3' ORF probe: a 942-bp PCR fragment amplified from BAC20I24 with the primer pair 3.4gwf (AAGAAACGCGATCTGGATGAATGGG) and 3.4gwr (CAGCTGT AGCAGAGATACGTAAATC) and covering the region starting 4.6 $\mathrm{kb}$ downstream from the start codon. Probe $\mathrm{C}$ is the $3^{\prime}$ UTR probe: derived from a BamH1 subclone of BAC20I24 and covering 400 bp immediately downstream from the stop codon. For nucleic acids manipulations standard procedures were used (Sambrook and Russell 2001). DNA sequencing was done by BaseClear (Leiden).

\section{BAC library screening, BAC fingerprinting, and contig building}

The $P$. infestans BAC library was screened as described by Jiang et al. (2005). To obtain BAC fingerprint patterns, $1 \mu \mathrm{g}$ of BAC DNA was digested with restriction enzymes and the fragments were visualized by gel electrophoresis. For contig building fragments from different BACs but sharing identical length were considered as common fragments.

\section{Reverse transcriptase-PCR analysis}

For RT-PCR, $10 \mu \mathrm{g}$ total RNA was treated with 4 units RQ1 RNasefree DNase (Promega) at $37^{\circ} \mathrm{C}$ for $1 \mathrm{~h}$ to remove genomic DNA. The first-strand cDNA was synthesized using oligo dT (16) and Superscript II reverse transcriptase for $30 \mathrm{~min}$ at $40^{\circ} \mathrm{C}$ (Gibco$\mathrm{BRL})$. Sequence-specific primers were used in the subsequent $\mathrm{PCR}$ with cDNA as template with 30 cycles $\left(30 \mathrm{sec}\right.$ at $94^{\circ} \mathrm{C}, 30 \mathrm{sec}$ at $56^{\circ} \mathrm{C}-60^{\circ} \mathrm{C}$, and $60 \mathrm{sec}$ at $72^{\circ} \mathrm{C}$ ). The RT-PCR primers that were used are based on the TDF3.1 sequence (GenBank accession DW010104) (TDF3.1f: ACTGCATCACACCATCAG and TDF3.1r: GCCGAACAATAGCTCATG), and the TDF3.4 sequence (GenBank accession DW010117) (TDF3.4f: AGCTGGTTGAAGCGCGAC and TDF3.4r: GGAAGGCCGGAGAGCGTC).

\section{AFLP and cDNA-AFLP}

AFLP was performed as described by van der Lee et al. (1997) using the restriction enzyme combination EcoRI/MseI and primers with two selective bases. cDNA-AFLP was performed as described by Dong et al. (2004) and Guo et al. (2006). The nomenclature of AFLP and cDNA-AFLP markers is according to van der Lee et al. (1997), Dong et al. (2004), and Guo et al. (2006).

\section{The Phytophthora GeneChip}

The Syngenta custom designed Phytophthora GeneChip is an Affymetrix array containing 19,324 unique sequences of which 18,256 represent unigenes. The sequences were generated from a large scale EST project and represent 75,757 ESTs obtained from libraries from a wide range of growth conditions, stress responses, and developmental stages (Randall et al. 2005) (http://www. pfgd.org/). Over $82 \%$ of the sequences on the GeneChip are from $P$. infestans.

\section{Bulked segregant analysis using the Phytophthora GeneChip}

For bulked segregant analysis (BSA) RNA of F1 progeny with similar or overlapping AVR phenotypes was pooled. Pools were constructed as described by Guo et al. (2006). To probe the custom- designed Phytophthora GeneChip, a total of six RNA samples (four pools and two unpooled samples; Supplemental Table S2) was used. cDNA synthesis, array hybridization, and intensity normalization were performed similar to the methods described by $\mathrm{Zhu}$ et al. (2001). Array clones showing at least a twofold induction of hybridization intensity with probes from avirulent isolates as compared with probes from virulent isolates were chosen as candidates.

\section{Comparative genomic hybridization using the Phytophthora GeneChip}

For comparative genomic hybridization (CGH) the customdesigned Phytophthora GeneChip was hybridized with 14 independent genomic DNA samples representing six F1 progeny and two $P$. infestans field isolates, 88069 and 90128 , both unrelated to the mapping population. From strain T30-2, three independent genomic DNA samples were isolated from three separate cultures. Similarly from each of the strains T15-5, D12-17, T20-4, D12-6, 88069 , and 90128, two independent DNA samples were isolated. Genomic DNA was purified on a continuous cesium chlorideethidium bromide gradient as described by Sambrook and Russell (2001) and fluorescently labeled using the random priming method with BioPrime kit (Invitrogen). In brief, a total of $2 \mu \mathrm{g}$ of genomic DNA from each sample was used to mix with the $20 \times$ random primer solutions and denatured at $99^{\circ} \mathrm{C}$ for $5 \mathrm{~min}$. Following the immediate cooling to $4^{\circ} \mathrm{C}, 5 \mu \mathrm{L}$ of $10 \times \mathrm{dNTP}$ mix with biotin-labeled dCTP and $1 \mu \mathrm{L}$ of Klenow fragment were added to the reaction, and incubated at $37^{\circ} \mathrm{C}$ for $2 \mathrm{~h}$. Labeled DNA fragments were then assayed by gel electrophoresis, and fragments in a size range of 100-200 bp were applied to the GeneChip for hybridization. Reproducible differences in hybridization intensity between samples reflect copy number variations (CNV) in the different strains. Array clones showing at least twofold increase in intensity in one strain as compared with another were considered to have variable copy numbers in different strains. For each array clone, the relative intensity was calculated by dividing the individual absolute intensity by the average intensity of the 14 samples. As an indication of the intensity change within the 14 samples, the standard deviation value was calculated from the 14 relative intensities. Array clones with a standard deviation $>0.5$ were considered to represent a gene with CNV.

\section{Acknowledgments}

This work was financially supported by grants from the Netherlands Organization for Scientific Research (NWO-Aspasia 015.000.057) and EU-BioExploit (FOOD-CT-2005-513959). We kindly thank Syngenta, in particular Tong Zhu, Makoto Ono, and George Aux, for making the Syngenta custom designed Phytophthora GeneChip available and for performing the GeneChip hybridizations. We are grateful to Jun Guo for help with selecting the TDFs, Pierre de Wit for critically reading the manuscript, and Harold Meijer for many helpful suggestions.

\section{References}

Alfano, J.R. and Collmer, A. 2004. Type III secretion system effector proteins: Double agents in bacterial disease and plant defense. Annu. Rev. Phytopathol. 42: 385-414.

Alfano, J.R., Charkowski, A.O., Deng, W.L., Badel, J.L., Petnicki-Ocwieja, T., van Dijk, K., and Collmer, A. 2000. The Pseudomonas syringae Hrp pathogenicity island has a tripartite mosaic structure composed of a cluster of type III secretion genes bounded by exchangeable effector 
and conserved effector loci that contribute to parasitic fitness and pathogenicity in plants. Proc. Natl. Acad. Sci. 97: 4856-4861.

Al-Kherb, S.M., Fininsa, C., Shattock, R.C., and Shaw, D.S. 1995. The inheritance of virulence of Phytophthora infestans to potato. Plant Pathol. 44: 552-562.

Armstrong, M.R., Whisson, S.C., Pritchard, L., Bos, J.I., Venter, E., Avrova, A.O., Rehmany, A.P., Bohme, U., Brooks, K., Cherevach, I., et al. 2005. An ancestral oomycete locus contains late blight avirulence gene $A v r 3 a$, encoding a protein that is recognized in the host cytoplasm. Proc. Natl. Acad. Sci. 102: 7766-7771.

Birch, P.R., Rehmany, A.P., Pritchard, L., Kamoun, S., and Beynon, J.L. 2006. Trafficking arms: Oomycete effectors enter host plant cells. Trends Microbiol. 14: 8-11.

Bourke, A. 1993. The visitation of god? The potato and the great Irish famine. Lilliput Press, Dublin.

Carter, D.A., Buck, K.W., Archer, S.A., Van der Lee, T., Shattock, R.C. and Shaw, D.S. 1999. The detection of nonhybrid, trisomic, and triploid offspring in sexual progeny of a mating of Phytophthora infestans. Fungal Genet. Biol. 26: 198-208.

Cvitanich, C., Salcido, M., and Judelson, H.S. 2006. Concerted evolution of a tandemly arrayed family of mating-specific genes in Phytophthora analyzed through interspecific and intraspecific comparisons. Mol. Genet. Genomics 275: 169-184.

Dong, W., Latijnhouwers, M., Jiang, R.H.Y., Meijer, H.J.G., and Govers, F. 2004. Downstream targets of the Phytophthora infestans $\mathrm{G} \alpha$ subunit PiGPA1 revealed by cDNA-AFLP. Mol. Plant Pathol. 5: $483-494$.

Donn, G., Tischer, E., Smith, J.A., and Goodman, H.M. 1984. Herbicide-resistant alfalfa cells: An example of gene amplification in plants. J. Mol. Appl. Genet. 2: 621-635.

Drenth, A., Tas, I.C.Q., and Govers, F. 1994. DNA-fingerprinting uncovers a new sexually reproducing population of Phytophthora infestans in the Netherlands. Eur. J. Plant Pathol. 100: 97-107.

Drenth, A., Janssen, E.M., and Govers, F. 1995. Formation and survival of oospores of Phytophthora infestans under natural conditions. Plant Pathol. 44: 86-94.

Field, L.M., Devonshire, A.L., and Forde, B.G. 1988. Molecular evidence that insecticide resistance in peach-potato aphids (Myzus persicae Sulz.) results from amplification of an esterase gene. Biochem. J. 251: 309-312.

Flor, H.H. 1942. Inheritance of pathogenicity of Melampsora lini. Phytopathology 32: 653-669.

Goodwin, S.B., Spielman, L.J., Matuszak, J.M., Bergeron, S.N., and Fry, W.E. 1992. Clonal diversity and genetic differentiation of Phytophthora infestans populations in Northern and Central Mexico. Phytopathology 82: 955-961.

Goodwin, S.B., Smart, C.D., Sandrock, R.W., Deahl, K.L., Punja, Z.K., and Fry, W.E. 1998. Genetic change within populations of Phytophthora infestans in the United States and Canada during 1994 to 1996: Role of migration and recombination. Phytopathology 88: 939-949.

Gouget, A., Senchou, V., Govers, F., Sanson, A., Barre, A., Rougé, P., Pont-Lezica, R., and Canut, H. 2006. Lectin receptor kinases participate in protein-protein interactions to mediate plasma membrane-cell wall adhesions in Arabidopsis thaliana. Plant Physiol. 140: 81-90.

Gu, W.K., Spielman, L.J., Matuszak, J.M., Aist, J.R., Bayles, C.J., and Fry, W.E. 1993. Measurement of nuclear DNA contents of Mexican isolates of Phytophthora infestans. Mycol. Res. 97: 857-860.

Guo, J., Jiang, R.H.Y., Kamphuis, L.G., and Govers, F. 2006. A cDNA-AFLP based strategy to identify transcripts associated with avirulence in Phytophthora infestans. Fungal Genet. Biol. 43: 111-123.

Huang, S.W., Vleeshouwers, V., Werij, J.S., Hutten, R.C.B., van Eck, H.J., Visser, R.G.F., and Jacobsen, E. 2004. The R3 resistance to Phytophthora infestans in potato is conferred by two closely linked $R$ genes with distinct specificities. Mol. Plant Microbe Interact. 17: $428-435$.

Jiang, R.H.Y. 2006. "Footprints of evolution: The dynamics of effector genes in the Phytophthora genome." Ph.D. thesis. Wageningen University, The Netherlands.

Jiang, R.H., Dawe, A.L., Weide, R., van Staveren, M., Peters, S., Nuss, D.L., and Govers, F. 2005. Elicitin genes in Phytophthora infestans are clustered and interspersed with various transposon-like elements. Mol. Genet. Genomics 273: 20-32.

Jiang, R.H.Y., Tyler, B.M., Whisson, S.C., Hardham, A.R., and Govers, F. 2006. Ancient origin of elicitin gene clusters in Phytophthora genomes. Mol. Biol. Evol. 23: 338-351.

Jones, B.D. 2005. Salmonella invasion gene regulation: A story of environmental awareness. J. Microbiol. (Spec.) 43: 110-117.

Judelson, H.S. 1996. Chromosomal heteromorphism linked to the mating type locus of the oomycete Phytophthora infestans. Mol. Gen.
Genet. 252: 155-161.

Leach, J.E. and White, F.F. 1996. Bacterial avirulence genes. Annu. Rev. Phytopathol. 34: 153-179.

Lengauer, C., Kinzler, K.W., and Vogelstein, B. 1998. Genetic instabilities in human cancers. Nature 396: 643-649.

Lucito, R., Healy, J., Alexander, J., Reiner, A., Esposito, D. Chi, M., Rodgers, L., Brady, A., Sebat, J., Troge, J., et al. 2003. Representational oligonucleotide microarray analysis: A high-resolution method to detect genome copy number variation. Genome Res. 13: 2291-2305.

McDonald, B.A. and Linde, C. 2002. The population genetics of plant pathogens and breeding strategies for durable resistance. Euphytica 124: $163-180$.

McLeod, A., Smart, C.D., and Fry, W.E. 2004. Core promoter structure in the oomycete Phytophthora infestans. Eukaryot. Cell 3: 91-99.

Nicholls, H. 2004. Stopping the rot. PLoS Biol. 2: e213.

Orbach, M.J., Farrall, L., Sweigard, J.A., Chumley, F.G., and Valent, B. 2000. A telomeric avirulence gene determines efficacy for the rice blast resistance gene Pi-ta. Plant Cell 12: 2019-2032.

Patthy, L. 2003. Modular assembly of genes and the evolution of new functions. Genetica 118: 217-231.

Pieterse, C.M., Derksen, A.M., Folders, J., and Govers, F. 1994. Expression of the Phytophthora infestans ipiB and ipiO genes in planta and in vitro. Mol. Gen. Genet. 244: 269-277.

Randall, T.A., Dwyer, R.A., Huitema, E., Beyer, K., Cvitanich, C., Kelkar, H., Fong, A.M., Gates, K., Roberts, S., Yatzkan, E., et al. 2005. Large-scale gene discovery in the oomycete Phytophthora infestans reveals likely components of phytopathogenicity shared with true fungi. Mol. Plant Microbe Interact. 18: 229-243.

Rehmany, A.P., Gordon, A., Rose, L.E., Allen, R.L., Armstrong, M.R., Whisson, S.C., Kamoun, S., Tyler, B.M., Birch, P.R., and Beynon, J.L. 2005. Differential recognition of highly divergent downy mildew avirulence gene alleles by RPP1 resistance genes from two Arabidopsis lines. Plant Cell 17: 1839-1850.

Rohe, M., Gierlich, A., Hermann, H., Hahn, M., Schmidt, B., Rosahl, S., and Knogge, W. 1995. The race-specific elicitor, Nip1, from the barley pathogen, Rhynchosporium secalis, determines avirulence on host plants of the Rrs1 resistance genotype. EMBO J. 14: 4168-4177.

Romero, D. and Palacios, R. 1997. Gene amplification and genomic plasticity in prokaryotes. Annu. Rev. Genet. 31: 91-111.

Sambrook, J. and Russell, D.W. 2001. Molecular cloning: A laboratory manual. Cold Spring Harbor Laboratory Press, Cold Spring Harbor, NY.

Schell, M.A. 2000. Control of virulence and pathogenicity genes of Ralstonia solanacearum by an elaborate sensory network. Annu. Rev. Phytopathol. 38: 263-292.

Schmidt, H. and Hensel, M. 2004. Pathogenicity islands in bacterial pathogenesis. Clin. Microbiol. Rev. 17: 14-56.

Senchou, V., Weide, R., Carrasco, A., Bouyssou, H., Pont-Lezica, R. Govers, F., and Canut, H. 2004. High affinity recognition of a Phytophthora protein by Arabidopsis via an RGD motif. Cell. Mol. Life Sci. 61: 502-509.

Shan, W., Cao, M., Leung, D., and Tyler, B.M. 2004. The Avr1b locus of Phytophthora sojae encodes an elicitor and a regulator required for avirulence on soybean plants carrying resistance gene Rps1b. Mol. Plant Microbe Interact. 17: 394-403.

Spielman, L.J., McMaster, B.J., and Fry, W.E. 1989. Dominance and recessiveness at loci for virulence against potato and tomato in Phytophthora infestans. Theor. Appl. Genet. 77: 832-838.

Suijkerbuijk, R.F., Olde Weghuis, D.E., Van den Berg, M., Pedeutour, F., Forus, A., Myklebost, O., Glier, C., Turc-Carel, C., and Geurts van Kessel, A. 1994. Comparative genomic hybridization as a tool to define two distinct chromosome 12-derived amplification units in well-differentiated liposarcomas. Genes Chromosomes Cancer 9: 292-295.

Tooley, P.W. and Therrien, C.D. 1987. Cytophotometric determination of the nuclear DNA content of 23 Mexican and 18 non-Mexican isolates of Phytophthora infestans. Exp. Mycol. 11: 19-26.

Tordai, H., Nagy, A., Farkas, K., Bányai, L., and Patthy, L. 2005. Modules, multidomain proteins and organismic complexity. FEBS J. 272: 5064-5078.

Tower, J. 2004. Developmental gene amplification and origin regulation. Annu. Rev. Genet. 38: 273-304.

van der Lee, T., De Witte, I., Drenth, A., Alfonso, C., and Govers, F. 1997. AFLP linkage map of the oomycete Phytophthora infestans. Fungal Genet. Biol. 21: 278-291.

van der Lee, T., Robold, A., Testa, A., van't Klooster, J.W., and Govers, F. 2001a. Mapping of avirulence genes in Phytophthora infestans with amplified fragment length polymorphism markers selected by bulked segregant analysis. Genetics 157: 949-956.

van der Lee, T., Testa, A., van't Klooster, J., van den Berg-Velthuis, G., 
Jiang et al.

and Govers, F. 2001b. Chromosomal deletion in isolates of Phytophthora infestans correlates with virulence on R3, R10, and R11 potato lines. Mol. Plant Microbe Interact. 14: 1444-1452.

van der Lee, T., Testa, A., Robold, A., van't Klooster, J., and Govers, F. 2004. High-density genetic linkage maps of Phytophthora infestans reveal trisomic progeny and chromosomal rearrangements. Genetics 167: 1643-1661.

Vanhamme, L. and Pays, E. 1995. Control of gene expression in trypanosomes. Microbiol. Rev. 59: 223-240.

van Kan, J.A.L., van den Ackerveken, G.J.M., and de Wit, P.J.G.M. 1991. Cloning and characterization of cDNA of avirulence gene Avr9 of the fungal pathogen Cladosporium fulvum, causal agent of tomato leaf mold. Mol. Plant Microbe Interact. 4: 52-59.

van't Slot, K.A.E. and Knogge, W. 2002. A dual role for microbial pathogen-derived effector proteins in plant disease and resistance. Crit. Rev. Plant Sci. 21: 229-271.

van West, P., de Jong, A.J., Judelson, H.S., Emons, A.M.C., and Govers, F. 1998. The ipiO gene of Phytophthora infestans is highly expressed in invading hyphae during infection. Fungal Genet. Biol.

23: $126-138$.

Vissers, L.E., Veltman, J.A., Geurts van Kessel, A., and Brunner, H.G. 2005. Identification of disease genes by whole genome CGH arrays. Hum. Mol. Genet. (Spec. No. 2) 14: R215-R223.
Wastie, R.L. 1991. Breeding for resistance. In Advances in plant pathology (eds. D.S. Ingram and P.H. Williams), pp. 193-224. Academic Press, London.

Westerink, N., Brandwagt, B.F., de Wit, P.J., and Joosten, M.H. 2004. Cladosporium fulvum circumvents the second functional resistance gene homologue at the $\mathrm{Cf}-4$ locus $(\mathrm{Hcr} 9-4 \mathrm{E})$ by secretion of a stable avr4E isoform. Mol. Microbiol. 54: 533-545.

Whisson, S.C., van derLee, T., Bryan, G.J., Waugh, R., Govers, F., and Birch, P.R.J. 2001. Physical mapping across an avirulence locus of Phytophthora infestans using a highly representative, large-insert bacterial artificial chromosome library. Mol. Genet. Genomics 266: 289-295.

Zhu, T., Budworth, P., Han, B., Brown, D., Chang, H.S., Zou, G.Z. and Wang, X. 2001. Toward elucidating the global gene expression patterns of developing Arabidopsis: Parallel analysis of 8,300 genes by a high-density oligonucleotide probe array. Plant Physiol. Biochem. 39: 221-242.

Zwankhuizen, M.J., Govers, F., and Zadoks, J.C. 1998. Development of potato late blight epidemics: Disease foci, disease gradients, and infection sources. Phytopathology 88: 754-763.

Received February 6, 2006; accepted in revised form May 3, 2006.

840 Genome Research

www.genome.org 


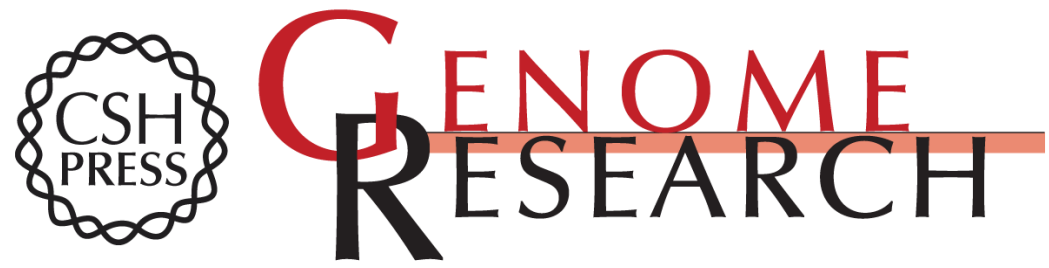

\section{Amplification generates modular diversity at an avirulence locus in the pathogen Phytophthora}

Rays H.Y. Jiang, Rob Weide, Peter J.I. van de Vondervoort, et al.

Genome Res. 2006 16: 827-840

Access the most recent version at doi:10.1101/gr.5193806

Supplemental http://genome.cshlp.org/content/suppl/2006/08/24/16.7.827.DC1

Material

References This article cites 58 articles, 12 of which can be accessed free at:

http://genome.cshlp.org/content/16/7/827.full.html\#ref-list-1

\section{License}

Email Alerting Receive free email alerts when new articles cite this article - sign up in the box at the Service top right corner of the article or click here.

\section{Affordable, Accurate Sequencing.}

